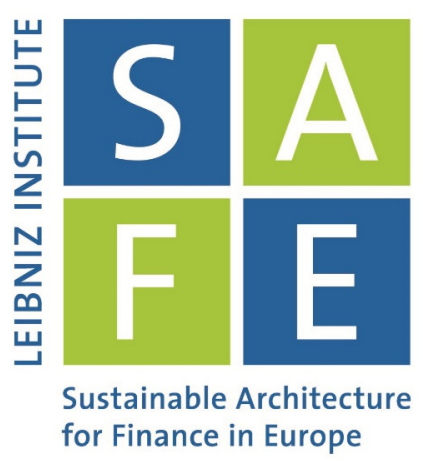

Christian Schlag | Michael Semenischev | Julian Thimme

\title{
Predictability and the Cross-Section of Expected Returns: A Challenge for Asset Pricing Models
}

SAFE Working Paper No. 289

\section{Leibniz Institute for Financial Research SAFE}

Sustainable Architecture for Finance in Europe 


\title{
Predictability and the Cross-Section of Expected Returns: A Challenge for Asset Pricing Models
}

This version: August 28, 2020

\begin{abstract}
Many modern macro finance models imply that excess returns on arbitrary assets are predictable via the price-dividend ratio and the variance risk premium of the aggregate stock market. We propose a simple empirical test for the ability of such a model to explain the cross-section of expected returns by sorting stocks based on the sensitivity of expected returns to these quantities. Models with only one uncertainty-related state variable, like the habit model or the long-run risks model, cannot pass this test. However, even extensions with more state variables mostly fail. We derive conditions under which models would be able to produce expected return patterns in line with the data and discuss various examples.
\end{abstract}

Keywords: Asset pricing, cross-section of stock returns, predictability

JEL: G12, E44, D81 


\title{
Predictability and the Cross-Section of Expected Returns: A Challenge for Asset Pricing Models
}

\author{
Christian Schlag* $\quad$ Michael Semenischev ${ }^{\dagger} \quad$ Julian Thimme $^{\ddagger}$
}

* Goethe University Frankfurt and Research Center SAFE, Theodor-W.-Adorno-Platz 3, 60323 Frankfurt, Germany. E-mail: schlag@finance.uni-frankfurt.de

$\dagger$ d-fine GmbH, An der Hauptwache 7, 60313 Frankfurt, Germany. E-mail: michael.semenischev@d-fine.de

$\ddagger$ Karlsruhe Institute of Technology, Blücherstr. 17, 76185 Karlsruhe, Germany. E-mail: thimme@kit.edu

The authors would like to thank Nikolai Gräber, Alexander Hillert, Christoph Meinerding, David Schreindorfer, Tyler Shumway (the editor), Ole Wilms, Amir Yaron, two anonymous referees, participants of the 45th Annual Meeting of the European Finance Association in Warsaw, the 32nd Annual Congress of the European Economic Association in Lisbon, the 20th Conference of the Swiss Society of Financial Market Research in Zurich, the 23rd Annual Meeting of the German Finance Association in Bonn, the 48th MMF Conference in Bath, and seminar participants at Frankfurt and Muenster for valuable comments and suggestions. 


\section{Introduction}

Macro asset pricing models such as the habit model (Campbell and Cochrane 1999) or the long-run risk model (Bansal and Yaron 2004) claim some success in jointly explaining many regularities of aggregate U.S. consumption and dividend claims. Key ingredients of these models are typically latent state variables, which in the background drive risk premia and other quantities like valuation ratios. The mechanism behind these model outputs is usually difficult to falsify, since state variables are not observable, and the model parameters necessary to fit empirical stylized facts are difficult to estimate. These facts constitute what has recently been called "dark matter" in asset pricing models (Chen et al. 2019). It is therefore vital to find new ways to investigate the plausibility of models and to come up with new testable implications.

Models with time-varying risk premia make statements not only about the expected return on the aggregate stock market, but also (implicitly or explicitly) about the cross-section of expected returns on individual stocks. We exploit this fact to come up with such new testable implications concerning the link between time-series and cross-sectional predictability. A generic asset pricing model implies that expected returns on arbitrary assets are functions of the state variables, as are the price-dividend ratio and the variance risk premium of the market. We suggest a simple empirical approach making use of exactly this fact by first regressing individual stock returns on the lagged price-dividend ratio and variance risk premium of the aggregate market, and then transforming the estimated slope coefficients into model-implied loadings on state variable innovations. When we perform univariate and bivariate sorts on these loadings, we find average return patterns in the data, which most models are not able to reproduce.

Our approach is motivated by the observation that excess returns on stocks and portfolios are predictable by the price-dividend ratio and the variance risk premium of the aggregate stock market. To exemplify this finding, Figure 1 shows regression coefficients and $R^{2}$ s from predictive 
regressions on these two predictors. As test assets we use 49 industry portfolios from Kenneth French's website and the market portfolio itself (marked by the dark gray bar). The $R^{2} \mathrm{~s}$ are large for many portfolios, and the slope coefficients are significant at the 5\%-level for about half of the portfolios in case of the price-dividend ratio and for all but four portfolios in case of the variance risk premium. Furthermore, there is considerable cross-sectional variation in the slope coefficients. Asset pricing models impose restrictions on the relation between these coefficients and expected returns.

Our main finding is that stocks with high coefficients with respect to either regressor tend to have high average returns, but that the cross-sectional rank correlation of the two sets of coefficients across stocks is significantly negative in the majority of months. This immediately implies that a model in which only one state variable causes expected excess returns to be timevarying (as it is the case in the models suggested by Campbell and Cochrane 1999, Bansal and Yaron 2004, Wachter 2013) is by construction not able to match the cross-sectional patterns in average returns in the data. ${ }^{1}$ Specifying a framework where at least two state variables drive the time variation in expected excess returns is thus a necessary, but still not a sufficient condition to explain the empirical stylized facts.

As a matter of fact, our results show that the two state variables have to exhibit very specific characteristics to allow the model to match the data. Most importantly, one of the state variables has to be positively related to the price-dividend ratio of the aggregate market. This feature is rare in asset pricing models building on endowment economies, since state variables driving the time variation in risk premia, like risk aversion, uncertainty, or disaster risk, typically have the property that an increase in any of them leads to lower valuation ratios.

Empirically, the relation between these quantities is less clear. While returns typically

\footnotetext{
${ }^{1}$ The long-run risks model, just as many of its extensions, also features a state variable that models the trend growth rate of consumption and dividends. This state variable is of minor relevance for expected excess returns and thus plays a negligible role for the purpose of our analysis.
} 
have negative exposures to realized volatility, Campbell et al. (2018) find that returns on all their 25 test portfolios have positive exposures to forward-looking volatility, backed out from a VAR. Production economy models such as Croce (2014) naturally imply that stock prices increase in uncertainty. The reason is that households consume less and save more after a positive shock to uncertainty. Thus, production economies naturally imply a positive relation between expected returns and slope coefficients with respect to the market price-dividend ratio.

Relative to production economies, endowment economies are easier to handle and make the economic channels that affect asset prices more explicit, which is helpful when considering all the empirical facts jointly. To exemplify the ingredients which are necessary to match them, we discuss two different endowment economy models. The model of Segal et al. (2015) features a state variable representing "good uncertainty", i.e., the upside potential of consumption innovations. In their model, the price-dividend ratio increases in good uncertainty, which, in combination with a second state variable for "bad uncertainty", allows the model to explain most of the patterns we find in the cross-section of expected stock returns.

As a second example, we discuss the model of Bekaert and Engstrom (2017), which features as state variables the variances of two shocks, each of which has an impact on both consumption and dividend growth. While high values of both state variables correspond to bad states in this model, dividends are a hedge against one of the risks affecting aggregate consumption growth. This makes the price-dividend ratio increase in one state variable, and, together with the second state variable, allows the model to explain the empirical facts we document. The key assumption, a negative relation between consumption and dividend growth in response to a certain type of shock, is rather non-standard and may appear counterintuitive. Productionbased models could thus provide a more natural rationale for the joint behavior of price-dividend ratios, variance risk premia and expected returns in the cross-section.

Our paper is structured as follows. In Section 2, we discuss the related literature. In 
Section 3, we introduce our empirical approach, provide information about the data set, and show the main empirical findings. Section 4 contains a more detailed empirical analysis as well as a number of robustness checks. In Section 5, we analyze models in which only one state variable drives time-variation in expected excess returns and show that, by their very construction, they are not able to produce the patterns we find in Sections 3 and 4. Afterwards, we discuss the ingredients necessary for a model to at least have a chance to explain the empirical stylized facts. Section 6 concludes. An Online Appendix provides additional information on the solutions of the different models and provides detailed quantitative analyses of the models of Bansal and Yaron (2004), Segal et al. (2015), and Bekaert and Engstrom (2017).

\section{Literature review}

Our paper is not the first to investigate the cross-section of expected returns in the context of macro asset pricing models. Barroso et al. (2017) show that the exposure of stocks to innovations in state variables predicting future consumption growth can explain cross-sectional variation in expected stock returns. They also find that risk premia are considerably higher in periods of high variance of the state variables. These findings can easily be explained within the longrun risks model of Bansal and Yaron (2004). There, the state variable $x$ predicts consumption growth, while time variation in the variance of $x$ (and thus in risk premia) is modeled via a second state variable $V$. Hence, the long-run risks model is a natural framework to study cross-sectional variation in risk premia.

Similarly, Boons (2016) also backs out state variables from observables. More directly, Bansal et al. (2005) empirically investigate the link between aggregate consumption growth and firms' cash flow growth and show that variation in consumption betas can explain a large share of the cross-sectional variation in expected returns. In a related paper, Boguth and Kuehn 
(2013) estimate expected consumption growth and consumption growth variance from the data and show that the exposure to consumption volatility risk predicts future returns. Dittmar and Lundblad (2017) study the link between firm characteristics and the exposure to consumption risk to explain the cross-section of expected returns. Tédongap (2015) develops and estimates a long-run risks model, and he shows that consumption volatility is an important factor when it comes to explaining cross-sectional asset pricing anomalies.

The habit model proposed by Campbell and Cochrane (1999) is also a natural framework to formalize the relation between the time variation in discount rates, consumption growth, and risk premia on the one hand, and the cross-section of expected stock returns on the other. Dou et al. (2020) also assume that households entertain habit preferences, which implies that times of high discount rates are times of low consumption growth. In their general equilibrium model, firms in industries with very persistent market leadership have particularly high exposures to discount rate shocks and, thus, higher expected returns. These firms also have on average higher profit margins and higher profitability. Thus, the framework of Dou et al. (2020) allows an interpretation of the exposure to discount rate shocks in terms of firm characteristics.

In contrast to all of these papers, we start with a model-free empirical approach. In particular, we do not have to estimate latent macro state variables or rely on consumption data (which may be prone to measurement errors, as discussed in, e.g., Kroencke (2017), Parker and Julliard (2005), and Savov (2011)) to estimate exposures of assets in the cross-section. The key idea in our approach is that expected returns on stocks with a strong exposure to certain shocks react more strongly to changes in the variance of these shocks. When we use the same predictors for all stocks, the strength of this reaction is quantified by the coefficients in predictive regressions. This allows us to remain silent about the ultimate sources of the variation in risk premia. The link between the ultimate macroeconomic risks and variation of expected returns in the cross-section is then solely provided by the respective theoretical models. 
An alternative approach to distinguishing between different macro asset pricing models was recently suggested by Zviadadze (2018). She uses Bayesian MCMC methods to estimate generalized VARs using data on aggregate stock market returns, dividends, consumption growth, and the price-dividend ratio of the aggregate market. The structures of the VARs, which feature latent state variables, are implied by different candidate models. Zviadadze (2018) introduces the concept of "incremental expected returns", which are generalized impulse response functions and allow to analyze the impact of different shocks on expected market returns over different horizons. She concludes that a specification that is in line with the model of Drechsler and Yaron (2011) explains the term structure of risk in expected returns well.

Our approach is related but differs from hers in two important aspects. First, we do not back out shocks to latent state variables using sophisticated econometric techniques. Thus, our approach is simpler and does not require consumption data with all the limitations mentioned above. The price we pay is that our approach does not allow conclusions about the type of shocks impacting expected returns (over different horizons), i.e., we cannot make firm statements about whether expected returns are driven by innovations in variance, jump intensities, or other economic variables. Second, Zviadadze (2018) considers the term structure of aggregate market returns and does not take the cross-section of stock returns into consideration. We do the exact opposite, i.e., we limit our analysis to one particular prediction horizon (per predictor) and consider the cross-sectional dimension of the return data. In this sense, our paper is the cross-sectional analogue to the time-series analysis of Zviadadze (2018). 


\section{Stylized empirical facts}

\subsection{Empirical approach}

We form portfolios of individual stocks based on their slope coefficients from predictive regressions. As predictors we consider the (log) price-dividend ratio and the variance risk premium of the aggregate stock market, denoted by $\omega$ and $\nu$, respectively. We account for the possibility of time-varying coefficients and perform a rolling-window analysis. In particular, at the beginning

of each month $t$, we look at the return history of a stock over the formation period $[t-72, t-1]$, i.e., over the preceding six years and run the regressions

$$
\begin{gathered}
r_{\tau, \tau+12}^{i}-r_{\tau, \tau+12}^{f}=a_{\omega, i, t}+b_{\omega, i, t} \omega_{\tau}+e_{\tau+12}^{\omega, i, t} \\
r_{\tau, \tau+4}^{i}-r_{\tau, \tau+4}^{f}=a_{\nu, i, t}+b_{\nu, i, t} \nu_{\tau}+e_{\tau+4}^{\nu, i, t}
\end{gathered}
$$

with $\tau$ ranging from $t-72$ to $t-11$ and to $t-3$ in regressions (1) and (2), respectively. Here, $r_{\tau, \tau+h}^{i}$ denotes the log return on stock $i$ when investing at time $\tau$ and holding it for $h$ months. $r_{\tau, \tau+h}^{f}$ denotes the risk-free return over the corresponding holding period.

We select a return horizon of 12 and 4 months for the price-dividend ratio and the variance risk premium, respectively, since predictive regressions based on these horizons are likely to yield informative slope coefficients $b_{\omega}$ and $b_{\nu}{ }^{2}$

We then sort stocks with respect to the estimated coefficients $\hat{b}_{\omega, i, t}$ and $\hat{b}_{\nu, i, t}$, respectively, and form decile portfolios. We hold the portfolios for one month and repeat the exercise at the beginning of month $t+1$. In addition, we also perform independent bivariate sorts, where we form 25 portfolios as the intersection of quintiles based on the estimates of the two $b$-coefficients.

\footnotetext{
${ }^{2}$ We discuss the choice of formation period and return horizons in Section A1.2 of the Online Appendix and show that our results are not specific to the particular values in regressions (1) and (2).
} 


\subsection{Data}

We use monthly returns on all publicly traded common stocks available in CRSP. We exclude stocks that are traded at venues other than AMEX, NYSE, or NASDAQ, penny stocks (i.e., stocks with a share price below $5 \$$ at the beginning of a month), and stocks of financials and utilities, as it is standard in the literature. Delisting returns are accounted for following Shumway (1997). We subtract the one-month Treasury bill rate (taken from Kenneth French's data library ${ }^{3}$ ) to calculate excess returns. Accounting data for individual stocks, used in Section 4 below, are taken from Compustat.

We use the price-dividend ratio of the aggregate stock market provided on Amit Goyal's webpage $^{4}$ and the variance risk premium taken from Hao Zhou's homepage. ${ }^{5}$ The former is defined as the ratio of the S\&P500 index and the 12-month moving sums of dividends paid by the index constituents. The latter is defined as the risk-neutral variance implied by prices of S\&P500 index options with a maturity of one month minus the lagged realized one-month return variance. The construction of this time series is discussed in detail in Bollerslev et al. (2009). For us, it is only important that we use the same time series in the predictive regressions for all stocks.

We use data from January 1933 until June 2018. Data on the variance risk premium are only available from 1990 onwards, hence, for a large part of our analysis, we rely on a sample starting in January 1990. To extend the sample backwards, we make use of the news implied volatility index (NVIX). Manela and Moreira (2017) construct this index by running a support vector regression of option implied volatility on the relative frequency of words used in the Wall Street Journal. For our purposes, we run a regression of the risk-neutral variance on NVIX and NVIX $^{2}$ for the period from 1990 to 2018 and obtain an $R^{2}$ of 0.77 . We use the estimated

\footnotetext{
${ }^{3}$ See http://mba.tuck.dartmouth.edu/pages/faculty/ken.french/data_library.html.

${ }^{4}$ See http://www.hec.unil.ch/agoyal.

${ }^{5}$ See https://sites.google.com/site/haozhouspersonalhomepage.
} 
coefficients from this regression and the values for NVIX and NVIX ${ }^{2}$ in the period from 1933 to 1990 to compute a proxy for the risk neutral variance and subtract the realized variance, again taken from Amit Goyal's webpage, to obtain a proxy for the variance risk premium before 1990.

\subsection{Results}

\subsubsection{The relation between slope coefficients and returns}

This section describes the returns on the portfolios sorted according to the procedure outlined in Section 3.1 above. Further information concerning the time-series behavior of the portfolio returns, the relation between slope coefficients, and other portfolio characteristics as well as robustness analyses are provided in Section 4.

Table 1 shows the portfolio returns. $\mathrm{HML}_{\omega}$ and $\mathrm{HML}_{\nu}$ denote the portfolios long in stocks with high and short in stocks with low estimated slope coefficients from the respective predictive regressions. For both sorts, we find that the average return on the respective HML portfolio is positive. When we sort on $b_{\omega}$, i.e., the slope coefficient for the price-dividend ratio, this average return is significantly positive for both sample periods, with a value of 77 and 31 basis points per month over the 1990-2018 and the 1933-2018 sample, respectively. The corresponding numbers for the sort on $b_{\nu}$ are 54 and 30 basis points, where the latter is also statistically significant.

\subsubsection{The relation between $b_{\nu}$ and $b_{\omega}$}

We now study the cross-sectional relation between the predictive slope coefficients in more detail to get a better understanding of the similarities and differences between the two individual sorts. For that purpose, we calculate the cross-sectional rank correlation between $b_{\omega}$ and $b_{\nu}$ in every month. The time series of these correlation coefficients is shown in Graph A of Figure 2. Their median (average) is -0.20 (-0.13) over the 1990-2018 sample, with significantly negative 
values in $68 \%$ of the months. However, we also find a positive rank correlation in about $30 \%$ of the months. As can be seen from Figure 2, this is the case right before the recession in 2001 and during the financial crisis in 2008. Over the longer sample, we find median and average correlation coefficients which are still negative, but closer to zero, due to a long period between 1970 and the mid 1980's where the cross-sectional correlations were actually positive.

One may now ask what drives the time series behavior of the cross-sectional correlation? Graph B of Figure 2 shows 72-months rolling correlation coefficients between our two predictors, i.e., the price-dividend ratio and the variance risk premium. We observe a pattern that is very similar to the one in Graph A, which is a very intuitive finding. It is plausible that stocks whose future returns are positively related to innovations in the variance risk premium also have future returns that are positively related to innovations in the price-dividend ratio in periods when the variance risk premium and the price-dividend ratio are positively related and the other way around when the relation between the two predictors is negative. We observe the latter pattern in the majority of months, which is in line with the intuition from macro asset pricing models. The variance premium is high when uncertainty or risk aversion is high, and these models typically imply that the price-dividend ratio is low in these periods.

Table 2 shows the average relative number of stocks in portfolios resulting from an independent double sort based on the estimates for $b_{\omega}$ and $b_{\nu}$. In line with the on average negative rank correlations between $b_{\omega}$ and $b_{\nu}$, we find that in the shorter sample (Panel A), the highest number of stocks in each column and each row are assigned to the portfolios along the counterdiagonal. In addition, there are less pronounced clusters in the low $b_{\omega} /$ low $b_{\nu^{-}}$and the high $b_{\omega} /$ high $b_{\nu}$-portfolios, which correspond to the months with positive rank correlations discussed above. However, the overall pattern clearly suggests a negative unconditional correlation between the two sorting criteria. We observe a similar pattern in the longer sample (Panel B). 


\section{Further analyses and robustness}

\subsection{Time series properties of slope coefficients}

In this section we provide additional information about the rank correlation between $b_{\omega}$ and $b_{\nu}$ and discuss further time series properties of the slope coefficients. Graph A in Figure 2 suggests that the rank correlation between slope coefficients is quite persistent. The first order autocorrelation coefficient is 0.99 . This is not astonishing, given the fact that the slope coefficients themselves are very persistent due to the overlapping formation periods. The cross-sectional median first order autocorrelation is 0.92 and 0.81 for $b_{\omega}$ and $b_{\nu}$, respectively. This, in turn, leads to a very persistent portfolio composition. We analyze the persistence of a stock's portfolio number, i.e., the number of the decile portfolio that the stock was assigned to in the different months. The cross-sectional median first order autocorrelation coefficient of the portfolio number is 0.95 and 0.88 for sorts on $b_{\omega}$ and $b_{\nu}$, respectively.

Even with a very persistent portfolio allocation, there can still be periods in which many stocks change portfolios and subsequently remain in the new portfolio for an extended period of time. Since it is not really feasible to track individual stocks over time, we now look at what we call mode portfolios. For each stock, we calculate the mode of its portfolio number over the recent 12 months. We then sort stocks into portfolios with respect to this mode and study the average portfolio number for the stocks assigned to the different mode portfolios. A perfectly persistent portfolio allocation would imply that the average portfolio number is always equal to the mode of past portfolio numbers. In a period where all stocks are randomly reallocated, the average portfolio numbers of all mode portfolios is equal to 5.5.

The time series of average portfolio numbers across mode portfolios are shown in Figure 3. The figure shows these numbers for mode portfolios based on $b_{\omega}, b_{\nu}$, and, as a comparison, momentum. Momentum is a useful benchmark, since it is also based on past returns with 
portfolios formed every month and not just once a year, as in case of many sorts based on balance sheet information. The figure shows that the portfolio allocation is pretty stable for the sorts on slope coefficients, compared to momentum. However, in a few periods, considerable reallocation takes place. In case of $b_{\omega}$, these periods are in early 1964, mid 1996, and during the financial crisis in 2009. In case of $b_{\nu}$, these periods are in 1946/1947, early 1988, and during the recessions in 1973, 1982, and 2009. The dates 1946, 1964, 1988, and 1996 coincide with the dates of the reversal of the correlation between price-dividend ratio and variance risk premium from negative to positive or vice versa.

Intuitively, the two predictors and the conditional expected returns on stocks are driven by some latent state variables. A correlation reversal can be caused by a change in the conditional loadings of the predictors on the state variables. Such a change will automatically also affect the portfolio allocation for our sorts, since stocks that are strongly exposed to a certain state variable will now have a weaker or stronger relation with the predictor. The fact that the portfolio reallocation and the correlation reversal take place at the same time indicates that our sorts indeed pick up the exposures of the different stocks to latent state variables.

Our motivating example presented in the introduction shows that for industry portfolios most $b_{\omega}$ 's are negative, and all $b_{\nu}$ 's are positive. The picture is very similar for individual stocks and for the aggregate market, for which we perform the same rolling window predictive regressions as for the single stocks. Figure 4 shows the evolution of the breakpoints for the portfolio formation with respect to $b_{\omega}$ (upper graph) and $b_{\nu}$ (lower graph) together with the coefficient of the aggregate market over time. It becomes apparent that the interdecile range is much larger in some periods than in others. The reason is that the volatility of the predictor is much lower in these intervals which leads to larger absolute slope coefficients and a more pronounced spread between higher and lower values.

The main insight from Figure 4 is that $b_{\omega}$ is predominantly negative, while we observe the 
opposite for $b_{\nu}$. When we look at all the individual $b_{\omega}$ 's across firms and months for the sample period 1990-2018, we find that $66 \%$ of them are negative, and the cross-sectional median is also less than zero in $92 \%$ of the months, which is in line with the intuition from the predictive regressions for the aggregate market portfolio. For $b_{\nu}$, the corresponding numbers are $60 \%$ and $77 \%$. The $b_{\omega}$-coefficient of the market portfolio is negative in $86 \%$ of the months and exhibits a time-series correlation of $84 \%$ with the cross-sectional median. For $b_{\nu}$ we find a positive coefficient for the market in $91 \%$ of the months, and again a strong positive correlation of $58 \%$ with the cross-sectional median.

Over the longer sample, the statistics for $b_{\omega}$ are very similar to those for the shorter period. $b_{\nu}$ coefficients are predominantly negative between 1970 and the mid 1980's, where we also observe a positive local correlation between $b_{\omega}$ and $b_{\nu}$ and between the two predictors themselves.

\subsection{Relation to other firm characteristics}

Table 3 shows characteristics of the stocks in the portfolios sorted on the predictive slope coefficients. We report average characteristics in the most extreme decile portfolios and aggregate portfolios in the middle to groups of two. The sample period is 1990-2018. From Panel A, we first observe that the average $b_{\nu}$ coefficients are positive and decrease monotonically in $b_{\omega}$. A similar pattern can be observed for the average $b_{\omega}$ coefficients (which are negative though) across $b_{\nu}$-sorted portfolios in Panel B. This again shows the strongly negative average cross-sectional relation between $b_{\omega}$ and $b_{\nu}$ documented in Sections 3.3 and 4.1 above.

Market beta is inversely related to $b_{\omega}$. This finding is not astonishing, given the fact that the market portfolio itself exhibits a negative slope coefficient in predictive regressions on the price-dividend ratio. Under the (strongly simplifying) assumption that all systematic variation 
in returns is due to common variation in expected returns and price-dividend ratios driven by a single state variable, stocks which are more sensitive to changes in that state variable (i.e., have more negative $\left.b_{\omega}\right)$ must also have higher market betas. The same intuition applies to $b_{\nu}$, albeit with a switch in sign, since the market portfolio and the majority of stocks have a positive slope coefficient in predictive regressions on the variance risk premium. The positive cross-sectional relation between $b_{\nu}$ and market beta may explain the positive relation between $b_{\nu}$ and expected returns. We take a closer look at in-sample portfolio betas and alphas in Section 4.3.

With respect to market capitalization, we find inversely U-shaped patterns in $b_{\omega}$ and $b_{\nu}{ }^{6}$ For both predictors, we also find an inverse U-shape for the relation between the respective b-coefficient and the book-to-market ratio of equity as well as operating profitability. For investment and R\&D expenses scaled by sales we obtain the opposite picture, i.e., a U-shaped relation.

Recent asset pricing models provide guidance regarding the cross-sectional relation between slope coefficients and firm characteristics. For example, the model by Dou et al. (2020) suggests that highly profitable firms have stronger exposures to discount rate innovations and, thus, more negative $b_{\omega}$ 's. From the perspective of their model, we would expect average profitability to be decreasing in $b_{\omega}$. However, this intuition is only valid as long as an increase in discount rates leads to a decrease in the price-dividend ratio. In Section 5, we will discuss models that rationalize decreases but also increases in valuation ratios upon a given discount rate innovation, depending on the reason of that innovation, and, thus, potentially reconcile the patterns in characteristics and returns.

All of the U-shaped or reverse U-shaped patterns in average firm characteristics suggest that stocks in the most extreme decile portfolios should have low expected returns. For example,

\footnotetext{
${ }^{6}$ In Section A1.1 of the Online Appendix, we analyze if the relation between slope coefficients and returns is special to small stocks and find that this is not the case.
} 
for a given expected cash-flow, low investment suggests that future cash-flows are risky, since the firm would have a strong incentive to invest otherwise. ${ }^{7}$ Conversely, high profitability suggests high cash-flows relative to a low firm value, which again suggests that the cost of capital is high. In the light of the patterns in these four characteristics across $b$-sorted portfolios, it is not surprising that the returns on the low $b$-portfolios are low. At the same time, it is surprising that the returns on the high $b$-portfolios are high.

U-shaped patterns in average characteristics across portfolios can have (at least) two reasons. There can either be a U-shape in the majority of periods, or there can be a conditionally (non-linearly) increasing or decreasing relation, which then appears non-monotonic when unconditional averages are taken. When the latter explanation is correct, we should see only very few months in which the average characteristics of the firms in portfolios 1 and 10 are both above the cross-sectional average characteristic. In case of size, book-to-market, operating profitability, and R\&D expenses, we find conditionally U-shaped or inversely U-shaped patterns in the majority of months. ${ }^{8}$ An exception is investment, where we typically see a "smirk", i.e., a conditionally convex decreasing or increasing pattern. In case of $b_{\omega}$-sorted portfolios, we find a downward-sloping smirk in the majority of periods. The high investments of firms in the low $b_{\omega}$ decile portfolio is in line with the low returns that we observe.

In contrast to the characteristics mentioned so far, there is little variation in past returns across the $b$-sorted portfolios. This makes it unlikely that the patterns in average returns can be explained by a momentum effect. We will take a closer look at the exposures of the portfolios to risk factors (such as the momentum factor UMD) in the next section.

Figure A2 in the Online Appendix shows the average compositions of the ten $b_{\omega^{-}}$and $b_{\nu^{-}}$ sorted portfolios with respect to the industry classification represented by SIC codes. We do not

\footnotetext{
${ }^{7}$ This intuition has been formalized by Hou et al. (2015), among others.

${ }^{8}$ To give an example, in the case of $b_{\omega}$-sorted portfolios, we find that the average sizes of firms in both of the two extreme deciles are simultaneously below the cross-sectional average in $96 \%$ of the months.
} 
find a systematic pattern. We also perform portfolio sorts for each SIC code category separately. In all industry segments, we find patterns that are qualitatively similar to those shown in Table 1 , which shows that those patterns are not driven by stocks from certain industries.

\subsection{Time series properties of portfolio returns}

We start our analysis of the time series properties of portfolio returns by looking at the correlation between the two HML portfolios. Over the period from 1990 to 2018 they are moderately negatively correlated with a value of around -0.23 . Over the longer sample from 1933 to 2018, the correlation is rather weak and roughly equal to -0.03 . There is considerable variation in the conditional correlation, as indicated by Figure 5 showing correlations estimated over 72 -month rolling windows. The values for these conditional correlations range roughly between -0.8 and 0.4. Unsurprisingly, the time series behavior of this conditional correlation is very similar to that of the rank correlation between $b_{\nu}$ and $b_{\omega}$ (see Figure 2).

Table 4 shows the results of regressions of the decile portfolio returns on the factors MKT, SMB, HML $L_{\mathrm{BM}}$, RMW, and CMA from the Fama-French 5-factor model (see Fama and French (2016)), the momentum factor UMD (see Carhart (1997)), and the liquidity factor LIQ (see Pástor and Stambaugh (2003)). ${ }^{9}$ The table shows alphas and betas for the decile portfolios (where we again group the portfolios in the middle) as well as the alphas and factor exposures of the $\mathrm{HML}_{\omega}$ and $\mathrm{HML}_{\nu}$ portfolios, together with Newey and West (1987) $t$-statistics.

Alphas are increasing in $b_{\omega}$ and in $b_{\nu}$, and the alphas of the two HML portfolios are comparable to their average returns reported in Table 1 with respect to their magnitude and significance. ${ }^{10}$ In line with our earlier results we find a negative relation between $b_{\omega}$ and market

\footnotetext{
${ }^{9}$ We denote the standard Fama and French (1993) HML factor, i.e., the value factor, as $\mathrm{HML}_{\mathrm{BM}}$ (for bookto-market) to avoid confusion with $\mathrm{HML}_{\omega}$ and $\mathrm{HML}_{\nu}$.

${ }^{10}$ RMW and CMA are not available before 1963, and LIQ not before 1968, so we cannot perform the same analysis on the full sample between 1933 and 2018. However, the alphas on the $b_{\omega}$ - and $b_{\nu}$-sorted portfolios are
} 
betas and the opposite for $b_{\nu}$.

Regarding the exposures to the other factors, we find that they are U-shaped or inversely U-shaped, in line with the findings from the previous section. An exception is UMD, to which the $\mathrm{HML}_{\nu}$ portfolio has a negative exposure. This exposure explains the large positive alpha on the $b_{\nu}$-sorted portfolios, despite the monotonic relation between $b_{\nu}$ and market beta.

The finding that exposures to common factors do not explain the large positive return spreads between high and low $b_{\omega^{-}}$and $b_{\nu}$-portfolios is in line with recent evidence provided by Kozak et al. (2020). We now move in the opposite direction, i.e., we investigate if exposures to $\mathrm{HML}_{\omega}$ and $\mathrm{HML}_{\nu}$ help to explain the cross-sectional variation in returns on stocks and portfolios beyond standard factors.

Table 5 presents market price of risk estimates from a Fama and MacBeth (1973) regression of returns on different sets of test assets on exposures to the factors used in Table 4 as well as the new factors $\mathrm{HML}_{\omega}$ and $\mathrm{HML}_{\nu}$. As test assets we use single stocks as well as sets of 25 portfolios, double-sorted on size and a second characteristic, namely the book-to-market ratio, operating profitability, investment, or momentum. As an alternative set of test assets, we use 30 industry portfolios. $^{11}$

For single stocks, augmenting the common factor model by $\mathrm{HML}_{\omega}$ and $\mathrm{HML}_{\nu}$ increases the cross-sectional $R^{2}$ by a large amount, from -1.41 to -0.51 . It has to be noted, though, that both values are low because of the large variation in returns on single stocks. The market price of risk estimates of the new factors are insignificant when using single stocks as test assets, just as for some of the standard factors, such as SMB or HML $\mathrm{BM}$.

$0.71(t$-statistic of 2.80) and 0.64 ( $t$-statistic of 2.53), respectively, for the subsample from 1968 to 2018 . The factor exposures from this regression are similar to those reported in Table 4, except that both HML portfolios have significantly negative SMB betas.

${ }^{11}$ The portfolio returns are taken from Kenneth French's data library. Although it is more common in the literature to use portfolios rather than single stocks when estimating market prices of risks, Ang et al. (2020) argue that using portfolios does not lead to smaller standard errors of market price of risk estimates and comes at the cost of shrinking the dispersion in betas. We use both single stocks and portfolios. 
When using portfolios sorted on standard criteria as test assets, $\mathrm{HML}_{\omega}$ and $\mathrm{HML}_{\nu}$ help to reduce pricing errors relative to the existing factors in only a few cases. Exposures to $\mathrm{HML}_{\omega}$ help explain variation in returns to size and investment sorted portfolios, with a significantly positive market price of risk estimate and an increase in cross-sectional $R^{2}$ from 0.76 to 0.85 . The exposures to $\mathrm{HML}_{\nu}$ are negatively related to average returns on size and momentum-sorted portfolios, which is in line with the negative exposure of the $\mathrm{HML}_{\nu}$ portfolio to momentum. However, including $\mathrm{HML}_{\nu}$ into the factor model for pricing size and momentum-sorted portfolios does not increase the cross-sectional $R^{2}$ by much.

The findings for the sorted portfolios are not surprising. Table 3 already suggests that $b_{\omega}$ and $b_{\nu}$ do not line up with other characteristics such as book-to-market very well. As a consequence, there is little variation in $\mathrm{HML}_{\omega^{-}}$and $\mathrm{HML}_{\nu}$-exposures across, e.g., book-to-marketsorted portfolios.

\subsection{Robustness}

Section 1 of the Online Appendix contains several robustness tests. We find that our results are not caused by the presence of small stocks in our sample, that they hold for various alternative lengths of formation periods and return horizons, and that they are robust to variations in the regression design and the rebalancing intervals.

\section{Implications for macro asset pricing models}

\subsection{Models with one state variable}

The asset pricing literature has suggested a number of models that are able to solve the equity premium puzzle and are thus natural candidates for our study. The most prominent ones share 
the feature that the conditional expected excess return on any particular asset is a function of one single state variable within the model. Famous examples include long-run risks models (Bansal and Yaron (2004)), disaster models (Wachter (2013)), and models with habit formation (Campbell and Cochrane (1999)).

Models with a single state variable controling the time-variation in conditional expected returns are generally not capable of explaining the empirical stylized facts described in Section 3. The reason is as follows: A stock that yields a high unconditional expected excess return (relative to other stocks in the cross-section) is always also a stock whose conditional expected excess return is particularly sensitive to changes in the state variable. This sensitivity causes a relatively high absolute coefficient in regressions of future returns on the price-dividend ratio or on the variance risk premium of the aggregate market. The signs of the coefficients depend on the signs of the innovation in the respective predictor given a shift in the state variable. The results in Table 1 suggest that for both predictors high $b$ stocks are also high return stocks. This implies that stocks that have large coefficients in predictive regressions using the pricedividend ratio as a predictor also have large coefficients when using the variance risk premium as predictor. Our empirical findings in Sections 3 and 4 suggest the opposite: High- $b_{\omega}$ stocks are typically low- $b_{\nu}$ stocks, and vice versa.

To illustrate this rationale more explicitly, we now discuss the relationship between slope coefficients in predictive regressions and the cross-section of expected returns in the context of the three macro models mentioned above.

\subsubsection{Long-run risks}

In the classic long-run risks model introduced by Bansal and Yaron (2004) the distribution of future cash-flows is time-varying and depends on the conditional expected growth rate $x_{t}$ and the conditional variance $V_{t}$ of consumption growth. We consider a variant of the model where 
$V_{t}$ follows a square-root process to make the variance risk premium time-varying. The model implies that expected excess returns are approximately linear in $V_{t}$. Using an exact numerical solution, it can be shown that $x_{t}$ has only a negligible impact on the time variation in expected excess returns. Further examples of long-run risks models where one state variable drives timevariation in risk premia are the models of Eraker and Shaliastovich (2008) and Tauchen (2011).

The rationale of return predictability within the model is that the price-dividend ratio and the variance risk premium move when there is a shock to $V_{t}$. At the same time, expected returns on an arbitrary asset $i$ changes, making returns predictable in the time series. Section A2 of the Online Appendix derives the equations

$$
\begin{aligned}
\mathbb{E}_{t}\left[r_{t, t+1}^{i}\right]-r_{t, t+1}^{f} & =\pi_{i, V} V_{t}, \\
\omega_{t}^{m} & =A_{m, 0}+A_{m, x} x_{t}+A_{m, V} V_{t}, \\
\nu_{t}^{m} & =B_{m, V} V_{t} .
\end{aligned}
$$

The coefficients $\pi_{i, V}$ are the key to understanding the cross-section of expected returns, since unconditional expected returns are given by $\pi_{i, V} \bar{V}$, with $\bar{V}$ denoting the long-run mean of the state variable $V$. Just like $A_{m, 0}, A_{m, x}, A_{m, V}$, and $B_{m, V}$, the coefficient $\pi_{i, V}$ can be calculated in closed form as shown in the Online Appendix.

The slope coefficients $b_{\omega, i}$ and $b_{\nu, i}$ in Equations (1) and (2) are given by

$$
\begin{aligned}
& b_{\omega, i}=\frac{\operatorname{Cov}\left(r_{t, t+12}^{i}-r_{t, t+12}^{f}, \omega_{t}^{m}\right)}{\operatorname{Var}\left(\omega_{t}^{m}\right)}=\pi_{i, V} A_{m, V} \frac{\operatorname{Var}\left(V_{t}\right)}{\operatorname{Var}\left(\omega_{t}^{m}\right)} \sum_{\tau=0}^{11} \kappa_{V}^{\tau} \\
& b_{\nu, i}=\frac{\operatorname{Cov}\left(r_{t, t+4}^{i}-r_{t, t+4}^{f}, \nu_{t}^{m}\right)}{\operatorname{Var}\left(\nu_{t}^{m}\right)}=\pi_{i, V} B_{m, V} \frac{\operatorname{Var}\left(V_{t}\right)}{\operatorname{Var}\left(\nu_{t}^{m}\right)} \sum_{\tau=0}^{3} \kappa_{V}^{\tau},
\end{aligned}
$$

where $\kappa_{V}$ denotes the persistence of $V$. These equations imply that unconditional expected 
excess returns are proportional to the slope coefficients $b_{\omega, i}$ and $b_{\nu, i}$ :

$$
\mathbb{E}\left[r^{i}-r^{f}\right]=\pi_{i, V} \cdot \bar{V}=\lambda_{\omega} \cdot b_{\omega, i}=\lambda_{\nu} \cdot b_{\nu, i}
$$

where $\lambda_{\omega}$ and $\lambda_{\nu}$ are constants independent of the specific asset $i$.

Any model calibration imposes restrictions on the sign and magnitude of the $\lambda$ 's. The original calibration of Bansal and Yaron (2004) implies that the market price of $V$-risk is negative (see the Online Appendix for details). Since the variance of $V$ is proportional to $V$ itself, the variance risk premium increases in economic uncertainty. For the price-dividend ratio, the negative market price of $V$-risk means that the coefficient $A_{m, V}$ is negative, i.e., prices decrease when economic uncertainty increases. A stock with high expected returns, i.e., a stock with a large $\pi_{i, V}$, will thus have a highly negative $b_{\omega}$ and a highly positive $b_{\nu}$. In terms of Equation (5), this means $\lambda_{\omega}<0$ and $\lambda_{\nu}>0$. Section 3, however, shows that stocks with greater slope coefficients have higher returns, which is at odds with a negative $\lambda_{\omega}$.

There are alternative calibrations which imply $\lambda_{\omega}>0$ and $\lambda_{\nu}>0$. These calibrations are in line with the single sorts on $b_{\omega}$ and $b_{\nu}$, but at odds with the fact the cross-sectional correlation between $b_{\omega}$ and $b_{\nu}$ is mostly negative. As shown in the Online Appendix (and approved by a simulation study), high $\pi_{i, V}$ stocks are then exactly stocks with high $b_{\omega}$ and also high $b_{\nu}$, so that the model implies a perfectly positive cross-sectional relation between $b_{\omega, i}$ and $b_{\nu, i}$.

\subsubsection{Rare disasters}

In the rare disasters model of Barro (2006), expected excess returns are constant, implying that returns are not predictable by the price-dividend ratio or the variance risk premium. However, the extension of Wachter (2013), featuring time-varying disaster risk, yields high expected excess returns whenever the risk of experiencing a disaster is high. We briefly discuss the economic 
intuition of the model and refer to Wachter (2013) for a more formal treatment.

The representative investor has Duffie and Epstein (1992) preferences, which is the continuous-time analogue of Epstein and Zin (1989) preferences, with a unit elasticity of intertemporal substitution. The growth rate of consumption is modeled as an i.i.d. diffusive process plus a jump component represented by a Poisson process with time-varying jump intensity $V_{t}{ }^{12}$ Dividends are assumed to be levered consumption, i.e. $D_{t}^{m}=C_{t}^{\phi_{m}}$, with $\phi_{m}>1$ as the leverage parameter. The most natural way to generate a cross-section of dividend claims in this economy is to assume that dividends of firm $i$ are given by $D_{t}^{i}=C_{t}^{\phi_{i}} \cdot{ }^{13}$ As shown by Wachter (2013), the conditional expected excess return over the next period is given by

$$
\mathbb{E}_{t}\left[r_{t, t+1}^{i}\right]-r_{t, t+1}^{f}=\pi_{i, 0}+\pi_{i, V} V_{t}
$$

As opposed to the long-run risks model, Equation (6) features two coefficients, $\pi_{i, 0}$ and $\pi_{i, V}$, which explain cross-sectional differences in expected returns. However, both are increasing functions of the leverage parameter $\phi_{i}$, which implies that high- $\pi_{i, V}$ stocks also exhibit high $\pi_{i, 0}$ 's and, thus, high unconditional expected returns.

From here on, the intuition for why the model fails to explain the stylized facts from Section 3 is analogous to the long-run risks model, when we replace a time-varying diffusive cash-flow volatility by a time-varying risk of a rare disaster. The standard calibration of the model implies that the price-dividend ratio of the market decreases while expected excess returns increase in disaster risk. This effect is more pronounced for high $\pi_{i, V^{-s t o c k s}}$. Thus, stocks with lower (i.e. more negative) slope coefficients in predictive regressions on the pricedividend ratio have higher unconditional expected returns.

\footnotetext{
${ }^{12}$ Wachter (2013) denotes the jump intensity by $\lambda_{t}$. To avoid confusion and to emphasize the similarities with the long-run risks model, we use $V_{t}$ instead.

${ }^{13}$ With this restriction, all log dividend growth is perfectly correlated across all assets in the economy. To avoid that feature, one may add an uncorrelated and thus unpriced shock to the dividend growth of asset $i$.
} 


\subsubsection{Habit formation}

Campbell and Cochrane (1999) introduce a model in which time-varying risk aversion drives time variation in risk premia. As opposed to the models with long-run risks and rare disasters reviewed above, they assume that consumption growth is i.i.d. and lognormal. However, instead of an Epstein and Zin (1989) utility function, the agent maximizes the function

$$
\mathbb{E}_{t}\left[\sum_{j=0}^{\infty} \exp (-j \delta) \frac{\left(C_{t+j}-H_{t+j}\right)^{1-\gamma}-1}{1-\gamma}\right]
$$

The preference parameters $\delta$ and $\gamma$ control the agent's pure time preference rate and her risk attitude. More specifically, Campbell and Cochrane (1999) show that the Arrow-Pratt measure of relative risk aversion is time-varying and equal to $\gamma \exp \left(-s_{t}\right)$, with $s_{t}$ being defined below. $H_{t}$ denotes the time-varying habit or subsistence level, such that $C_{t}>H_{t}$. Time variation in $H$ is modeled indirectly via the time variation in the log surplus consumption ratio

$$
s_{t}=\log \left(C_{t}-H_{t}\right)-\log \left(C_{t}\right)
$$

which is assumed to follow the process

$$
s_{t+1}=(1-\phi) \bar{s}+\phi s_{t}+\lambda_{t}\left(\Delta c_{t+1}-\overline{\Delta c}_{t+1}\right)
$$

$\lambda_{t}$ is always positive and chosen in a way such that the interest rate is constant.

In this model, the surplus consumption ratio $s$ is the only state variable. There is no closed-form solution for the model, but Campbell and Cochrane (1999) show that risk premia are increasing in risk aversion, i.e., decreasing in $s$. At the same time, the price-dividend ratio is increasing in this variable. As a consequence, the return on the market is predictable by the price-dividend ratio with a negative coefficient, just as observed in Section 4. 
We can again introduce a cross-section of dividend claims by considering claims that are levered to different degrees relative to the consumption claim. ${ }^{14}$ With this notion, more levered claims have higher unconditional expected returns. Moreover, their conditional expected returns are more sensitive to changes in the surplus consumption ratio, i.e., they have more negative slope coefficients $b_{\omega}$. This contradicts our empirical findings from Section 3 above.

\subsection{Necessary condition 1: More than one state variable}

Models in which conditional expected excess returns depend on a single state variable as in Equation (3) fail because they cannot reconcile the three main findings from Section 3, namely that $\pi_{i, V}$ needs to be positively correlated with both $b_{\omega}$ and $b_{\nu}$ in the cross-section to be in line with the single sorts, but that at the same time $b_{\omega}$ has to be negatively correlated with $b_{\nu}{ }^{15}$ The tight link between the cross-sectional correlations is loosened when there is a second state variable $W$ that impacts conditional expected returns, i.e., when

$$
\mathbb{E}_{t}\left[r_{t, t+1}^{i}\right]-r_{t, t+1}^{f}=\pi_{i, V} V_{t}+\pi_{i, W} W_{t} .
$$

For simplicity, assume that $V$ and $W$ are locally uncorrelated, that the price-dividend ratio of the market is only a function of $W$, i.e., $\omega_{t}=A_{m, 0}+A_{m, W} W_{t}$, and that the variance risk premium is only a function of $V$, i.e., $\nu_{t}=B_{m, 0}+B_{m, V} V_{t}$. In this simple case, the slope coefficients $b_{\omega, i}$ and $b_{\nu, i}$ are proportional to $\pi_{i, W}$ and $\pi_{i, V}$, respectively, i.e.,

$$
b_{\omega, i}=k_{\omega} A_{m, W} \pi_{i, W}
$$

\footnotetext{
${ }^{14}$ Campbell and Cochrane (1999) assume that dividends and consumption are equal, i.e. that claims to all cash-flows are traded.

${ }^{15}$ For ease of exposition, we only consider a linear relation between expected returns and the state variable here. Most of the conclusions carry over to the non-linear case, as long as the relations between state variables and expected returns are monotonic.
} 
and

$$
b_{\nu, i}=k_{\nu} B_{m, V} \pi_{i, V}
$$

where $k_{\omega}$ and $k_{\nu}$ are coefficients which do not depend on $i$.

Given this, a model will reproduce the monotonicity in expected returns from the single sorts, when $k_{\omega} A_{m, W}$ and $k_{\nu} B_{m, V}$ are both positive. To be in line with the negative crosssectional rank correlations between slope coefficients, one may simply assume that $\pi_{i, V}$ and $\pi_{i, W}$ are negatively correlated in the cross-section.

Macro asset pricing models typically imply that the price-dividend ratio is a function of all state variables, rather than only $W$ as in the above example. Replacing the assumption $\omega_{t}=A_{m, 0}+A_{m, W} W_{t}$ by the assumption $\omega_{t}=A_{m, 0}+A_{m, V} V_{t}+A_{m, W} W_{t}$ implies that $b_{\omega, i}$ is a linear combination of $\pi_{i, V}$ and $\pi_{i, W}$. As a consequence, there is a cross-sectional correlation between $b_{\omega, i}$ and $b_{\nu, i}$ even without making assumptions on the joint cross-sectional distributions of $\pi_{i, V}$ and $\pi_{i, W}$. Thus, analyzing the cross-section of slope coefficients and returns in the context of a macro asset pricing model is typically more involved than suggested above.

A famous example of a model where two state variables drive the time variation in expected returns is the model of Drechsler and Yaron (2011). The model is an extension of the long-run risks model suggested by Bansal and Yaron (2004), in the sense that also in Drechsler and Yaron (2011) the representative agent has Epstein and Zin (1989) preferences, and consumption growth features a persistent component and is heteroskedastic. ${ }^{16}$ The volatility structure, however, is more involved, which allows the authors to explain the high and timevarying variance risk premium and its predictive power in the data. In particular, the stochastic variance of consumption growth, denoted $V$ here, has a time-varying central tendency, denoted

\footnotetext{
${ }^{16}$ There is a large number of alternative models that could also serve as examples, since they have qualitatively similar implications for the relation between coefficients from predictive regressions and the cross-section of expected returns. Examples are Bansal and Shaliastovich (2010), Bollerslev et al. (2009), Bollerslev et al. (2010), Drechsler (2013), Jin (2015), and Shaliastovich (2015).
} 
$W$. Moreover, there are several jumps with intensities that are assumed to be functions of $V$. The exact dynamics are presented in Section A3 of the Online Appendix, together with an extensive discussion of the model solution.

Using a standard calibration of the model, we find that the price-dividend ratio and the variance risk premium of the market portfolio are both functions of both state variables. However, the price-dividend ratio is first and foremost driven by the central tendency $W$, which in turn has only a negligible impact on the variance risk premium. Time variation in the latter is driven by innovations in $V$. For the slope coefficients, this means that $\pi_{i, W}$ is more important for $b_{\omega, i}$, while $\pi_{i, V}$ is more relevant for $b_{\nu, i}$. Quantitatively,

$$
\begin{aligned}
& b_{\omega, i}=-0.15 \pi_{i, V}-0.85 \pi_{i, W} \\
& b_{\nu, i}=0.95 \pi_{i, V}+0.05 \pi_{i, W},
\end{aligned}
$$

where we standardize the coefficients to make them sum to \pm 1 to facilitate the interpretation.

The model unambiguously implies a positive cross-sectional correlation between $b_{\nu, i}$ and expected returns, because $b_{\nu, i}$ increases in both $\pi_{i, V}$ and $\pi_{i, W}$. It also implies that stocks with high $b_{\nu, i}$ have low $b_{\omega, i}$, unless there is a very strong negative cross-sectional correlation between $\pi_{i, V}$ and $\pi_{i, W}$. Moreover, since $\pi_{i, V}$ and $\pi_{i, W}$ are typically positive for reasonable parameterizations of the dividend claims, the majority of $b_{\omega}$ 's will be negative, while most of the $b_{\nu}$ 's will have a positive sign.

Still, the model is not in line with the empirical findings from Section 3, because it implies that stocks with high $b_{\omega}$ 's have low expected returns. Economically, an increase in consumption volatility $V$ and in the central tendency $W$ of the volatility process are bad news for the investor, in the sense that the wealth-consumption ratio decreases in $V$ and $W$. Importantly, the price-dividend ratio also decreases with positive innovations to $V$ or $W$. At the same time, 
risk premia increase and thus expected excess returns on single stocks also go up. This increase is particularly large for relatively risky stocks with high unconditional expected excess returns. As a consequence, stocks with more negative coefficients in predictive regressions on the market price-dividend ratio will have higher unconditional returns, which is at odds with the data.

\subsection{Necessary condition 2: Good uncertainty, or dividends as a hedge}

How can a model generate a positive cross-sectional relation between slope coefficients $b_{\omega, i}$ and unconditional expected returns? We now exclusively discuss this question and, for that purpose, focus on a single state variable, denoted by $V_{t}$, which is assumed to have a substantial impact on the price-dividend ratio of the market portfolio. The unconditional expected excess return on stock $i$ is high, relative to other stocks in the cross-section, when $\pi_{i, V}$ is high. In case we would run a predictive regression of the returns on stock $i$ on $V_{t}$ directly, the slope coefficient would be relatively large. This implies that the price-dividend ratio of the market must be an increasing function of $V_{t}$ in order to also generate a relatively large slope coefficient in predictive regressions on the price-dividend ratio.

To structure the discussion, we distinguish between the cases of $V$ representing "good" and "bad" uncertainty, in the sense of whether the wealth-consumption ratio increases or decreases in $V$. In the first case, $V$ could, e.g., represent the variance of a shock to consumption where the shock has strictly positive support, so that $V$ could be interpreted as an upside potential in consumption. Alternatively, $V$ could stand for the likelihood of a disruptive technological innovation which leads to an upward jump in aggregate consumption. The latter idea has been put forward in a number of recent papers. For example, Kogan and Papanikolaou (2014) argue that such shocks (called investment-specific technology shocks) can explain the value premium, and Dou (2017) builds a general equilibrium model in which uncertainty can increase or decrease valuation ratios, depending on the type of uncertainty (production vs. investment uncertainty) 
and on the degree of risk sharing. His model provides an endogenous channel that motivates the notion of "good uncertainty".

It is thus reasonable to assume that the wealth-consumption ratio and, given a positive relation between consumption and dividends, also the market price-dividend ratio would increase in $V$. Stocks in the cross-section can then be compared with respect to their exposure to the good shocks. Assume stock $j$ is not exposed to these shocks, i.e., its price-dividend ratio and, thus, its conditional expected return would not react to innovations in $V$. This implies that in the setting assumed here the slope coefficient in a predictive regression on the market price-dividend ratio is zero (unless there are further state variables which we ignore in this section). Moreover, stock $j$ will not carry a risk premium.

Assume that some other stock $h$ has an exposure to good shocks that is positive and even greater than that of the aggregate market portfolio. Stock $h$ would then carry a large positive unconditional risk premium, since its return is positively related to a shock that has a positive market price of risk. Moreover, its conditional expected return would increase in $V$ and, thus, we would find a large positive slope coefficient in predictive regressions on the market price-dividend ratio.

While these channels jointly imply a positive relation between $b_{\omega, i}$ and $\pi_{i, W}$ in the crosssection, they also imply positive coefficients $b_{\omega, i}$ for the majority of stocks and, in particular, for the market portfolio. This is at odds with the results presented in Section 4.1, where we showed that these coefficients are typically negative in the data.

To match this stylized fact, the exposures to a further state variable $W$ can help. Assume the market price-dividend ratio is decreasing in $W$, and all stocks in the cross-section exhibit large and positive $\pi_{i, W}$ 's. In the simplest case, assume that $\pi_{i, W}=\pi_{m, W}$ for all stocks, then the slope coefficients $b_{\omega, i}$ may all be negative and vary in the cross-section due to different exposures to the good shock. 
Segal et al. (2015) propose a model that features two state variables driving conditional risk premia. We review the model and analyze its implications for the relation between slope coefficients from predictive regressions and the cross-section of expected returns in Section A4 of the Online Appendix. We find that the model is able to reproduce the pairwise cross-sectional correlations between $b_{\omega, i}, b_{\nu, i}$, and unconditional expected excess returns $\mathbb{E}\left[r^{i}-r^{f}\right]$. However, it implies that most of the slope coefficients $b_{\omega, i}$ and the slope coefficient $b_{\omega, m}$ of the market portfolio are positive, which is at odds with the findings from Section 4.1.

Intuitively, consumption growth is subject to two different shocks, both of which are heteroskedastic. The variances of the shocks are given by two state variables, $V$ and $W$, and expected consumption growth is time-varying with a persistent component $x$ as in Bansal and Yaron (2004). The key economic mechanism in the model is that innovations in $V(W)$ are positively (negatively) correlated with shocks in $x$. As a consequence, positive innovations in $V$ are good news to the investor, in the sense that the wealth-consumption ratio increases, justifying the term "good uncertainty" for $V$. In line with the wealth-consumption ratio, the price-dividend ratio of the market also increases in $V$ for standard calibrations of the model.

The priced risks that are related to $V$ in the model carry a positive premium, so that stocks with a stronger exposure to these risks have higher returns on average. Conditional expected returns on these stocks are also more sensitive to changes in $V$, so that they have more pronounced slope coefficients. Importantly, the slope coefficients are positive, since the market price-dividend ratio and risk premia are positively related to $V$. As a consequence, there is a positive relation between $b_{\omega, i}$ and expected returns in the cross-section, just as documented in Table 1. However, the fact that the slope coefficients $b_{\omega, i}$ are positive contradicts our findings from Section 4.1 .

We now discuss the second case where a high $V$-state is a bad state for the investor. This situation corresponds to the standard intuition from the majority of macro asset pricing 
models. Typically, $V$ quantifies economic uncertainty, the probability of a rare disaster, or time-varying risk aversion. For example, an increase in consumption growth volatility lets the price of the claim to aggregate consumption decrease, due to the investor's aversion to risk. The price-dividend ratio, however, would have to increase in this situation to be in line with our empirical findings. Such a pattern naturally occurs when dividends constitute a hedge for consumption risk. The investor can buy the market portfolio to insure against consumption risk and this hedging instrument is particularly valuable when consumption is very risky, i.e., when $V$ is high.

Stocks in the cross-section can then be compared based on how well they hedge consumption risk. Assume stock $j$ is not exposed to consumption risk at all, i.e., a shock to $V$ does not change its conditional expected return. Hence, the slope coefficient in a predictive regression on the market price-dividend ratio will be zero (just like in the first case). The expected return on stock $j$ will be relatively high, because stock $j$ does not hedge consumption risk.

Assume that some other stock $h$ is a better hedge than the market portfolio. When $V$ increases, the price-dividend ratio of stock $h$ will increase by even more than for the market and expected excess returns on stock $h$ decrease strongly. Accordingly, stock $h$ will have a very negative slope coefficient in predictive regressions on the market price-dividend ratio. Moreover, it will also have relatively low unconditional expected returns, because it hedges a source of priced risk.

Just like in the first case, this rationale can explain the positive cross-sectional relation between $b_{\omega}$ and $\pi_{V}$ and, as opposed to the first case, it naturally implies a negative $b_{\omega, i}$ for the majority of stocks, and a negative $b_{\omega, m}$. We show in Section A5 of the Online Appendix that the model of Bekaert and Engstrom (2017) generates such a pattern when using the original calibration. The agent in their model has habit formation preferences as in Campbell and Cochrane (1999) and cash-flows are subject to two different shocks whose variances are 
modeled using two separate variance processes, $V$ and $W$. While this feature is similar to the model of Segal et al. (2015), expected consumption growth is constant in the model of Bekaert and Engstrom (2017). Thus, innovations in $V$ and $W$ are bad news to the investor, in the sense that the wealth-consumption ratio decreases in the two state variables.

The key channel that allows the model to produce a positive relation between slope coefficients $b_{\omega}$ and expected returns, is that aggregate dividend growth is negatively affected by one of the two shocks that positively affect consumption growth. This feature of the model is somewhat counterintuitive and does not have an obvious micro foundation. Bekaert and Engstrom (2017) argue that it is important to match the joint dynamics of consumption and dividend growth in the data, especially the positive but rather low correlation between consumption and dividend growth. ${ }^{17}$ As a consequence, dividends hedge one type of consumption risk. The hedge is particularly valuable when uncertainty is high. Thus, the price dividend ratio of the aggregate stock market increases in the state variable $V$ and the intuition discussed above applies.

Endowment economy models are reduced-form models in the sense that they specify the joint dynamics of cash-flows and state variables exogenously. To study if an increase in the price of the market portfolio as a response to increased uncertainty is plausible, we now discuss a production-based model, where the trade-off between consumption and investment is an endogenous outcome of the solution of the agent's optimization problem. Croce (2014) suggests a model in which an agent with Epstein and Zin (1989) preferences has to decide on how much to consume and on how much to work in a given period $t$. As is standard in production economies, today's consumption and investment in the capital stock are financed by today's output, which means that the agent has to trade off an increase in today's utility via higher consumption against a higher capital stock in the future which leads to a higher future output.

\footnotetext{
${ }^{17}$ Both, consumption and dividend growth, are by assumption only affected by the two shocks. A positive relation of dividend and consumption growth with both shocks would imply an almost perfect correlation between the two. Adding a third (unpriced) shock to dividend growth would break this tight link without imposing the negative relation discussed above.
} 
Similarly, the agent's utility today increases in leisure, but output, and thus the continuation utility of future consumption, increase in hours worked. Apart from this, the way how capital translates into output is also governed by a stochastic productivity growth rate. Here, it is assumed that this growth rate is heteroskedastic with an exogenously specified mean-reverting state variable modeling the variance of productivity shocks. The exact model specification is presented in Section A6 of the Online Appendix.

Under Epstein and Zin (1989) utility with a preference for early resolution of uncertainty, the agent generally dislikes uncertainty. More precisely, a state of high productivity volatility is a high marginal utility state. Croce (2014) finds that the agent's response to an increase in the volatility of productivity growth is to work more, consume less and invest more. This behavior is in line with a standard precautionary savings motive. It is not specific to Croce's model but a general feature of production-based models. Due to the high investment, the value of the firm's capital increases when there is an increase in productivity growth volatility. Due to capital adjustment costs, consumption volatility also increases in productivity growth volatility. Hence, the model provides an economic rationale for why the price-dividend ratio of the market portfolio can increase in consumption volatility.

This important model implication is empirically supported by Campbell et al. (2018), who estimate a VAR to back out volatility news. On a sample starting in 1963, they find that the returns on all 25 portfolios, sorted with respect to book-to-market and size, have positive exposures to volatility news. They emphasize that it is important in this context to distinguish between forward looking and realized volatility (the exposures of realized returns to realized volatility are negative). Their findings suggest that uncertainty can either be good news to investors or that equity claims provide a hedge against certain shocks, which is particularly valuable in times of pronounced uncertainty. 


\section{Conclusion}

Excess returns on single stocks are often predictable by their price-dividend ratios and their variance risk premia. We show that there is also predictive power when we regress future returns on single stocks on the price-dividend ratio and variance risk premium of a broad stock market index. Naturally, the coefficients from these predictive regressions vary in the cross-section. We show that this variation contains information about the cross-sectional differences in expected returns. Stocks with high regression coefficients have high returns on average, no matter if we use the price-dividend ratio or the variance risk premium as a predictor. Moreover, stocks with high coefficients with respect to the price-dividend ratio typically have low coefficients with respect to the variance risk premium. This finding constitutes an important restriction for asset pricing models, or, put differently, it represents a model test.

Standard asset pricing models imply that stocks with large regression coefficients (in absolute terms) have strong exposures to latent fundamental macro risks and must thus have higher average returns. We show that the relation between coefficients and excess returns in the data is incompatible with models where only one state variable drives time variation in risk premia. In these models, stocks with high coefficients with respect to the price-dividend ratio also exhibit high coefficients with respect to the variance risk premium. This is inconsistent with the negative cross-sectional rank correlation between slope coefficients. Hence, we can reject standard models like Campbell and Cochrane (1999), Bansal and Yaron (2004), and Wachter (2013) with respect to their ability to explain the cross-section of average stock returns.

More strikingly, even models where expected excess returns are functions of two state variables usually fail to produce the patterns found in the data. The reason is that with standard parameters needed to match the usual unconditional asset pricing moments, high uncertaintystates are usually bad states, such that equity prices fall when uncertainty increases. This leads 
to a negative relation between state variables and the price-dividend ratio, while the variance risk premium loads positively on them.

We argue that there needs to be at least one state variable in the economy that is on average positive and has the following properties: First, it has an impact on the time-variation of expected returns and, second, it is positively related to the price-dividend ratio of the aggregate market. This implies that stock returns with high slope coefficients in regressions on the pricedividend ratio would also have high slope coefficients in regressions on the state variable itself, and, thus, that the unconditional expected returns on these stocks are high. Production-based asset pricing models, for example the model of Croce (2014), naturally imply these characteristics. In times of high uncertainty, when conditional risk premia are high, it is optimal for the agent to invest more and, by that, increase the capital stock of the firm, resulting in a higher price-dividend ratio of the market portfolio.

In endowment economy models, we have to make rather particular assumptions to generate a positive relation between uncertainty and the market price-dividend ratio. One of these assumptions can be that highly uncertain states are good states in general, in the sense that the wealth-consumption ratio and the price-dividend ratio increase in this form of uncertainty, which justifies the term "good uncertainty". For example, in the model of Segal et al. (2015) an increase of good uncertainty comes with an increase in growth prospects. This channel is combined with a second state variable that models "bad uncertainty" and is negatively related to the price-dividend ratio, but positively related to the variance risk premium. The model is able to explain the pairwise correlations between the different slope coefficients and expected returns. However, it implies a positive slope coefficient in a predictive regression of the market return on the market price-dividend ratio, which is at odds with the data.

Alternatively, when highly uncertain states are bad states, the price-dividend ratio can still be high in these states, if the dividend claim hedges a form of consumption risk. For example, in 
the model of Bekaert and Engstrom (2017), there are two sources of risk influencing consumption growth, one of which can be hedged by holding the market portfolio. In total, the model is able to explain the stylized facts from the empirical part of our paper. This is remarkable given that the model and the calibration suggested by Bekaert and Engstrom (2017) were not tailored to do so. However, it is questionable whether the exact economic mechanism of this model is plausible, given the particular structure of consumption and dividend growth dynamics that is crucial to reconcile our empirical findings. Production-based models could provide a more natural rationale to explain the joint behavior of price-dividend ratios, variance risk premia, and expected returns in the cross-section. 


\section{References}

Ang, A., J. LiU, AND K. Schwarz (2020): "Using stocks or portfolios in tests of factor models," Journal of Financial and Quantitative Analysis, forthcoming.

Bansal, R., R. Dittmar, and C. Lundblad (2005): "Consumption, Dividends, and the CrossSection of Equity Returns," Journal of Finance, 60, 1639-1672.

Bansal, R. And I. Shaliastovich (2010): "Confidence Risk and Asset Prices," American Economic Review, Papers and Proceedings, 100, 537-541.

Bansal, R. And A. Yaron (2004): "Risks for the Long-Run: A Potential Resolution of Asset Pricing Puzzles," Journal of Finance, 59, 1481-1509.

Barro, R. (2006): "Rare Disasters and Asset Markets in the Twentieth Century," Quarterly Journal of Economics, 2006, 823-866.

Barroso, P., M. Boons, And P. Karehnke (2017): "Time-varying State Variable Risk Premia in an ICAPM," Journal of Financial Economics, forthcoming.

Bekaert, G. And E. Engstrom (2017): "Asset Return Dynamics Under Habits and Bad Environment-Good Environment Fundamentals," Journal of Political Economy, 125, 713-760.

Boguth, O. And L. Kuehn (2013): "Consumption Volatility Risk," Journal of Finance, 68, 25892615.

Bollerslev, T., N. Sizova, And G. Tauchen (2010): "Volatility in Equilibrium: Asymmetries and Dynamic Dependencies," Review of Finance, 16, 31-81.

Bollerslev, T., G. Tauchen, And H. Zhou (2009): "Expected Stock Returns and Variance Risk Premia," Review of Financial Studies, 22, 4463-4492.

Boons, M. (2016): "State Variables, Macroeconomic Activity and the Cross Section of Individual Stocks," Journal of Financial Economics, 119, 489-522.

Campbell, J. And J. Cochrane (1999): "By Force of Habit: A Consumption-Based Explanation of Aggregate Stock Market Behavior," Journal of Political Economy, 107, 205-251.

Campbell, J. Y., S. Giglio, C. Polk, And R. Turley (2018): "An Intertemporal CAPM with Stochastic Volatility," Journal of Financial Economics, 128, 207-233.

Carhart, M. (1997): "On Persistence in Mutual Fund Performance," Journal of Finance, 52, 57-82.

Chen, H., W. Dou, And L. Kogan (2019): "Measuring the 'Dark Matter' in Asset Pricing Models," Working Paper. 
Croce, M. (2014): "Long-run Productivity Risk: A New Hope for Production-based Asset Pricing?" Journal of Monetary Economics, 66, 13-31.

Davis, J., E. FAma, And K. French (2000): "Characteristics, Covariances, and Average Returns: 1929 to 1997," Journal of Finance, 55, 389-406.

Dittmar, R. And C. Lundblad (2017): "Firm Characteristics, Consumption Risk, and Firm-level Risk Exposures," Journal of Financial Economics, 125, 326-343.

Dou, W. (2017): "Embrace or Fear Uncertainty: Growth Options, Limited Risk Sharing, and Asset Prices," Working Paper.

Dou, W., Y. Ji, And W. Wu (2020): "Competition, Profitability, and Discount Rates," Journal of Financial Economics, forthcoming.

Drechsler, I. (2013): "Uncertainty, Time-Varying Fear, and Asset Prices," Journal of Finance, 68, $1843-1889$.

Drechsler, I. And A. Yaron (2011): "What's Vol Got to Do With It," Review of Financial Studies, $24,1-45$.

Duffie, D. And L. Epstein (1992): "Stochastic Differential Utility," Econometrica., 353-394.

Epstein, L. And S. Zin (1989): "Substitution, Risk Aversion, and the Temporal Behaviour of Consumption and Asset Returns: A Theoretical Framework," Econometrica, 57, 937-969.

Eraker, B. And I. Shaliastovich (2008): “An Equilibrium Guide to Designing Affine Pricing Models," Mathematical Finance, 18, 519-543.

Fama, E. And K. French (1993): "Common Risk Factors in the Returns on Stocks and Bonds," Journal of Financial Economics, 33, 3-56.

- (2016): "Dissecting Anomalies with a Five-Factor Model," Review of Financial Studies, 29, 69-103.

Fama, E. And J. MacBeth (1973): "Risk, Return, and Equilibrium: Empirical Tests," Journal of Political Economy, 81, 607-636.

Hou, K., C. Xue, And L. Zhang (2015): "Digesting Anomalies: An Investment Approach," Review of Financial Studies, 28, 650-705.

JIN, J. (2015): "Jump-Diffusion Long-Run Risks Models, Variance Risk Premium, and Volatility Dynamics," Review of Finance, 19, 1223-1279. 
Kogan, L. And D. Papanikolaou (2014): "Growth Opportunities, Technology Shocks, and Asset Prices," Journal of Finance, 69, 675-718.

Kozak, S., S. Nagel, and S. Santosh (2020): "Shrinking the cross-section," Journal of Financial Economics, 135, 271-292.

Kroencke, T. (2017): "Asset pricing without garbage," Journal of Finance, 72, 47-98.

Manela, A. ANd A. Moreira (2017): "News implied volatility and disaster concerns," Journal of Financial Economics, 123, 137-162.

Newey, W. And K. West (1987): "A Simple, Positive Semi-definite, Heteroskedasticity and Autocorrelation Consistent Covariance Matrix," Econometrica, 55, 703-708.

Parker, J. And C. Julliard (2005): "Consumption Risk and the Cross Section of Expected Returns," Journal of Political Economy, 113, 185-222.

PÁstor, L. And R. F. Stambaugh (2003): "Liquidity Risk and Expected Stock Returns," Journal of Political Economy, 111, 642-685.

Savov, A. (2011): “Asset Pricing with Garbage," Journal of Finance, 66, 177-201.

Segal, G., I. Shaliastovich, And A. Yaron (2015): "Good and Bad Uncertainty: Macroeconomic and Financial Market Implications," Journal of Financial Economics, 117, 369-397.

Shaliastovich, I. (2015): "Learning, Confidence and Option Prices," Journal of Econometrics, 187, $18-42$.

Shumway, T. (1997): "The Delisting Bias in CRSP Data," Journal of Finance, 52, 327-340.

Tauchen, G. (2011): "Stochastic Volatility in General Equilibrium," Quarterly Journal of Finance, 1, 707-731.

TÉDongap, R. (2015): "Consumption Volatility and the Cross-Section of Stock Returns," Review of Finance, 19, 367-405.

Wachter, J. (2013): "Can Time-Varying Risk of Rare Disasters Explain Aggregate Stock Market Volatility?" Journal of Finance, 68, 987-1035.

Zviadadze, I. (2018): "Term Structure of Risk in Expected Returns," Working Paper. 


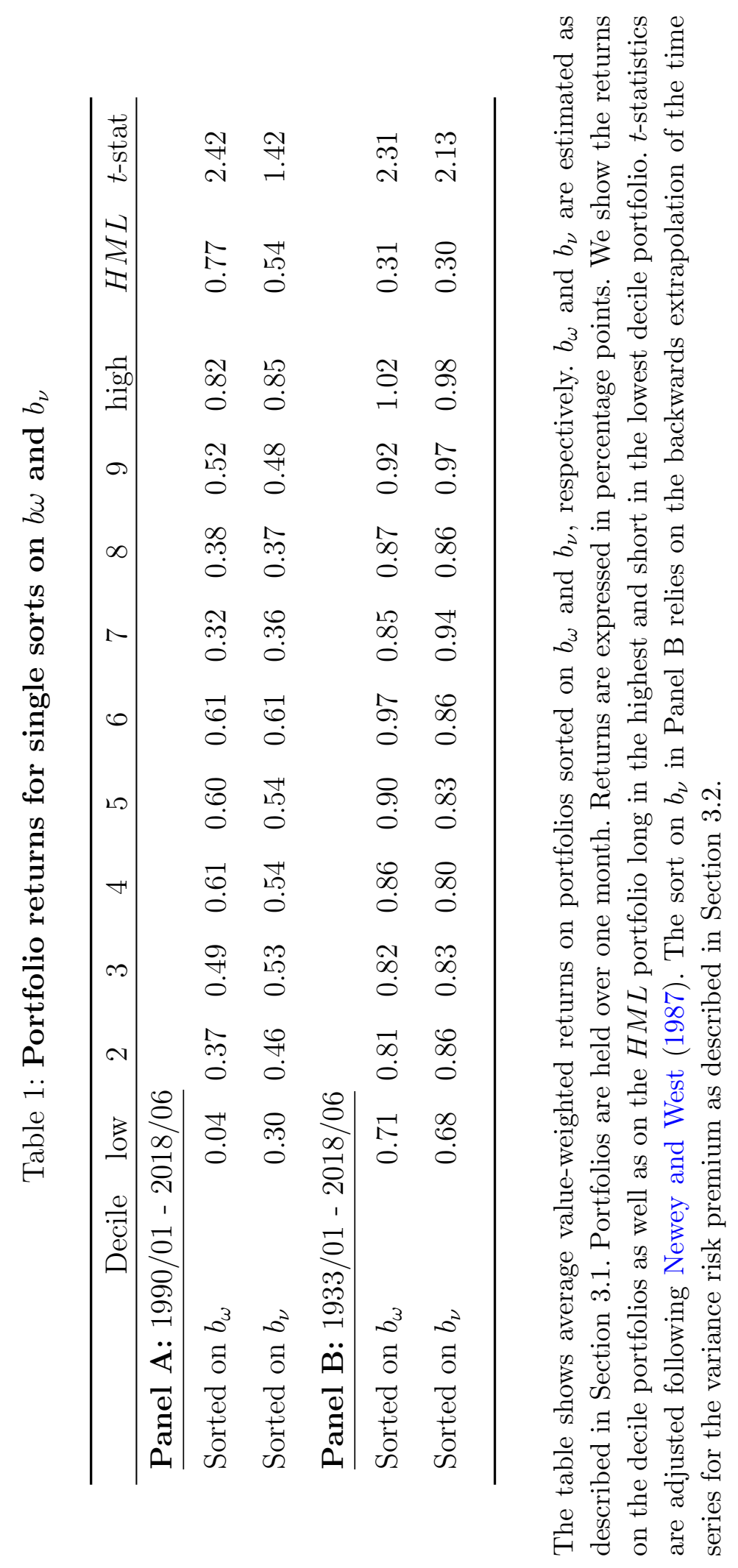


Table 2: Number of stocks in independently double-sorted portfolios

\begin{tabular}{cccccc}
\hline \multicolumn{7}{l}{ Panel A: $1990 / 01$} & $-2018 / 06$ \\
\hline \multicolumn{7}{c}{ low $b_{\omega}$} & 2 & 3 & 4 & high $b_{\omega}$ \\
low $b_{\nu}$ & 5.46 & 2.18 & 1.98 & 3.13 & 7.24 \\
2 & 3.31 & 4.18 & 4.20 & 4.72 & 3.60 \\
3 & 2.58 & 4.82 & 5.85 & 4.59 & 2.16 \\
4 & 2.97 & 5.30 & 5.19 & 4.32 & 2.22 \\
high $b_{\nu}$ & 5.68 & 3.52 & 2.79 & 3.24 & 4.78 \\
\hline \multicolumn{7}{l}{ Panel B: } & $1933 / 01$ & $-2018 / 06$ \\
\hline \multicolumn{7}{l}{ low $b_{\nu}$} & 5.88 & 2.78 & 2.22 & 2.97 & 6.16 \\
2 & 3.45 & 4.33 & 4.19 & 4.45 & 3.58 \\
3 & 2.56 & 4.60 & 5.44 & 4.72 & 2.68 \\
4 & 2.82 & 4.79 & 5.16 & 4.54 & 2.70 \\
high $b_{\nu}$ & 5.30 & 3.50 & 2.99 & 3.33 & 4.88 \\
\hline
\end{tabular}

The table shows the average relative frequency (in percent) of stocks in portfolios double-sorted independently w.r.t. $b_{\omega}$ and $b_{\nu} . b_{\omega}$ and $b_{\nu}$ are estimated as described in Section 3.1. Portfolios are held over one month. The sort on $b_{\nu}$ in Panel B relies on the backwards extrapolation of the time series for the variance risk premium as described in Section 3.2. 
Table 3: Characteristics across portfolios

\begin{tabular}{|c|c|c|c|c|c|c|}
\hline Characteristic & low & $2-3$ & $4-5$ & $6-7$ & $8-9$ & high \\
\hline \multicolumn{7}{|l|}{ Panel A: Sorted on $b_{\omega}$} \\
\hline$b_{\omega}$ & -6.78 & -2.24 & -0.96 & -0.26 & 0.61 & 3.82 \\
\hline$\times 100$ & 0.15 & 0.12 & 0.10 & 0.08 & 0.06 & 0.05 \\
\hline larket beta & 1.73 & 1.35 & 1.04 & 88 & 0.83 & 1.01 \\
\hline & 4.79 & 5.28 & 5.70 & 5.76 & 5.43 & 4.77 \\
\hline & 0.56 & 0.62 & 0.61 & 0.59 & .58 & 0.55 \\
\hline lity & 0.01 & 0 . & 0.22 & & & 0.05 \\
\hline & 0.21 & 0 & 0.12 & 1 & 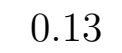 & 0.17 \\
\hline$R \&$ & 0.41 & 0. & 0.12 & 0.09 & 0 & 0.40 \\
\hline past & 0.07 & 0.08 & 0.10 & 0.10 & .12 & 0.11 \\
\hline \multicolumn{7}{|l|}{ Panel B: Sorted on $b_{\nu}$} \\
\hline 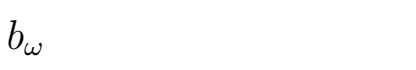 & -1.15 & -0.58 & -0.52 & -0.68 & -1.05 & -1.87 \\
\hline & -1.05 & -0.20 & 0.01 & 0.15 & 0.38 & 1.31 \\
\hline bot & 0.98 & $0 . £$ & 0.86 & 1.01 & 1.36 & 1.76 \\
\hline & 4.71 & 5.24 & 5.59 & 5.76 & 5.52 & 4.94 \\
\hline narket & 0.58 & 0.61 & 0.60 & 0.59 & 0.58 & 0.58 \\
\hline operating profitability & 0.04 & 0.18 & 0.22 & 0.22 & 0.17 & 0.04 \\
\hline investment & 0.17 & 0.14 & 0.12 & 0.12 & 0.13 & 0.17 \\
\hline R\&D expens & 0.48 & 0.17 & 0.11 & 0.12 & 0.17 & 0.32 \\
\hline past returns (12-2) & 0.07 & 0.10 & 0.10 & 0.10 & 0.10 & 0.09 \\
\hline
\end{tabular}

The table shows time series averages of the cross-sectional average characteristics of the stocks in portfolios sorted on $b_{\omega}$ and $b_{\nu}$. We show the characteristics for the bottom and top decile as well as for portfolios containing stocks in two deciles of the original sort each (2-3, 4-5, 6-7, and 8-9). $b_{\omega}$ and $b_{\nu}$ are estimated as described in Section 3.1. Market betas are estimated using data over the previous 60 months, as long as at least 24 monthly returns are available. Market equity is the log of the product of the number of shares outstanding and the price per share. Book equity, investment, and operating profitability are calculated as described in Davis et al. (2000) and Fama and French (2016). Past returns (12-2) denotes the return on an asset from one year to one month prior to the formation month. R\&D expenses are scaled by total assets. The sample period is 1990/01 - 2018/06 
Table 4: Alphas and factor exposures

\begin{tabular}{|c|c|c|c|c|c|c|c|c|}
\hline Factor & low & $2-3$ & $4-5$ & $6-7$ & $8-9$ & high & HML & $t$-stat \\
\hline \multicolumn{9}{|c|}{ Panel A: Sorted on $b_{\omega}$} \\
\hline$\alpha$ & -0.38 & -0.16 & -0.08 & -0.06 & 0.09 & 0.45 & 0.83 & 2.34 \\
\hline MKT & 1.25 & 1.09 & 1.01 & 0.93 & 0.93 & 1.07 & -0.18 & -1.70 \\
\hline SMB & 0.30 & 0.24 & 0.01 & -0.09 & -0.06 & 0.29 & -0.02 & -0.09 \\
\hline $\mathrm{HML}_{\mathrm{BM}}$ & -0.08 & 0.21 & 0.24 & 0.27 & 0.09 & -0.01 & 0.07 & 0.45 \\
\hline RMW & -0.66 & -0.05 & 0.25 & 0.00 & -0.28 & -0.75 & -0.09 & -0.36 \\
\hline CMA & -0.44 & -0.33 & -0.01 & -0.19 & -0.40 & -0.64 & -0.20 & -0.74 \\
\hline UMD & -0.04 & -0.02 & 0.03 & 0.03 & 0.04 & 0.13 & 0.17 & 0.83 \\
\hline LIQ & 0.08 & 0.07 & 0.04 & 0.05 & 0.05 & 0.03 & -0.04 & -0.56 \\
\hline \multicolumn{9}{|c|}{ Panel B: Sorted on $b_{\nu}$} \\
\hline$\alpha$ & -0.12 & -0.21 & -0.17 & -0.12 & -0.01 & 0.51 & 0.63 & 1.59 \\
\hline MKT & 0.90 & 0.98 & 0.94 & 0.98 & 1.14 & 1.25 & 0.35 & 2.31 \\
\hline SMB & 0.59 & 0.15 & 0.01 & -0.12 & 0.02 & 0.29 & -0.31 & -1.94 \\
\hline $\mathrm{HML}_{\mathrm{BM}}$ & 0.05 & 0.23 & 0.27 & 0.18 & 0.09 & 0.07 & 0.02 & 0.08 \\
\hline RMW & -0.60 & 0.17 & 0.24 & 0.08 & -0.35 & -0.88 & -0.28 & -1.50 \\
\hline CMA & -0.71 & -0.19 & -0.09 & 0.07 & -0.20 & -0.56 & 0.16 & 0.54 \\
\hline UMD & 0.25 & 0.13 & 0.08 & 0.04 & -0.08 & -0.19 & -0.44 & -4.22 \\
\hline LIQ & 0.10 & 0.06 & 0.07 & 0.04 & 0.04 & 0.03 & -0.06 & -0.61 \\
\hline
\end{tabular}

The table shows factor exposures and alphas of portfolios sorted on $b_{\omega}$ and $b_{\nu}$. We show these quantities for the bottom and top decile as well as for portfolios containing stocks in two deciles of the original sort each (2-3, 4-5, 6-7, and 8-9). $b_{\omega}$ and $b_{\nu}$ are estimated as described in Section 3.1. Factor exposures are estimated using contemporaneous time series regressions. The factors are the excess return on the market $(\mathrm{MKT})$, the size factor $(\mathrm{SMB})$, the value factor $\left(\mathrm{HML}_{\mathrm{BM}}\right)$, the operating profitability factor (RMW), the investment factor (CMA), the momentum factor (UMD), and the Pástor and Stambaugh (2003) liquidity factor (LIQ). The sample period is 1990/01 - 2018/06. 


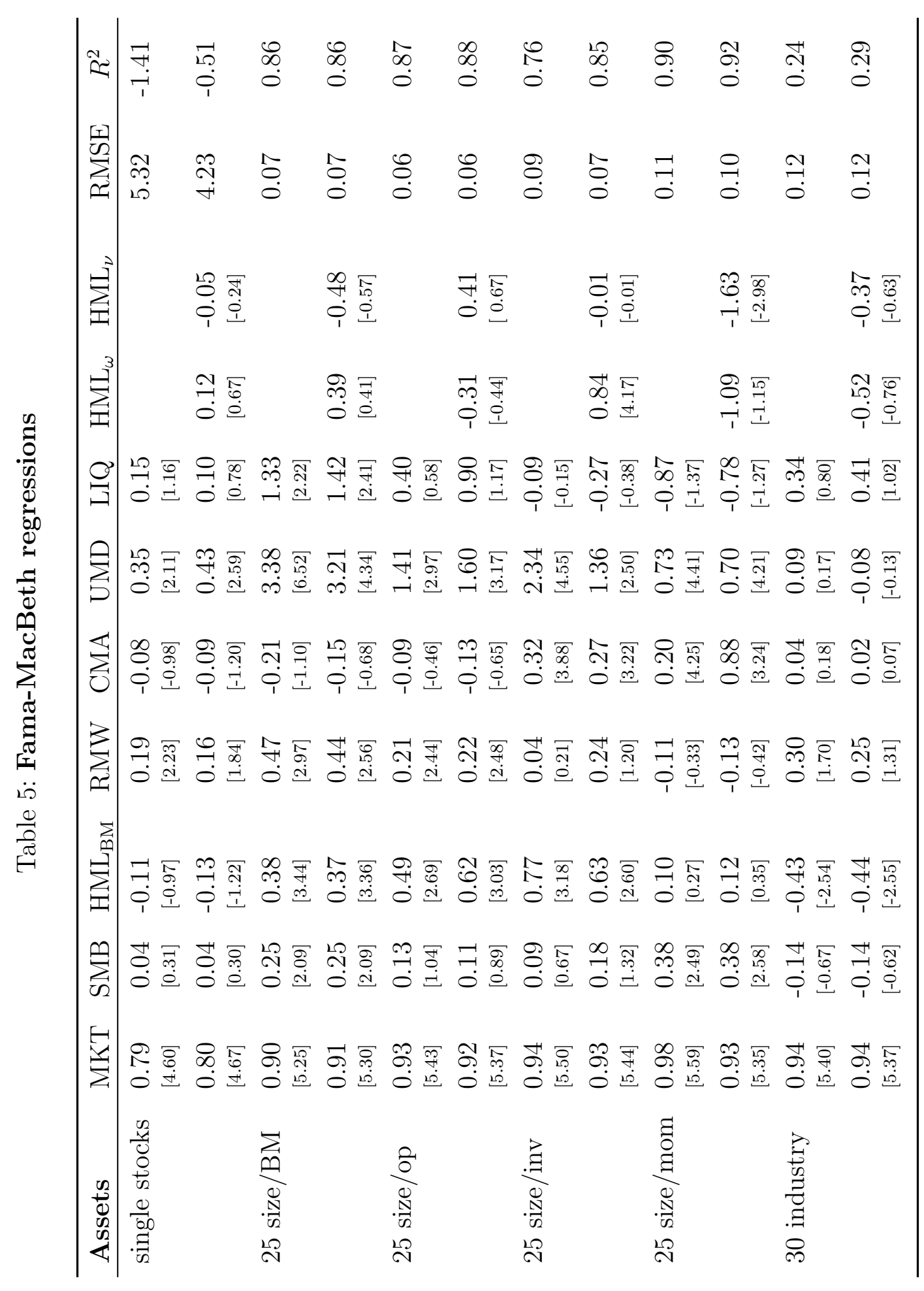

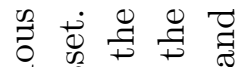

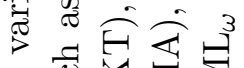



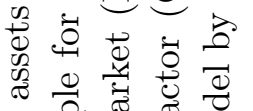

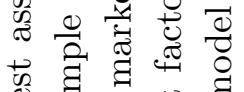

के द्वै

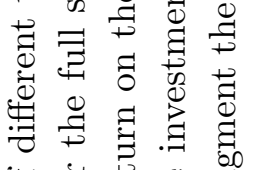

पे山्ग

告 0



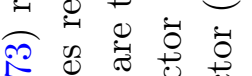

蛋

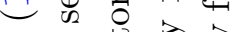



प

要

च

สี

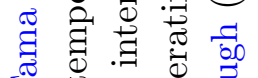

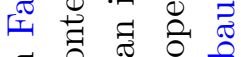

घี $0 \begin{gathered}0 \\ 0\end{gathered}$

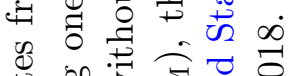

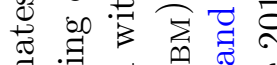

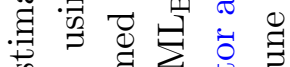

讨



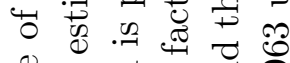

.

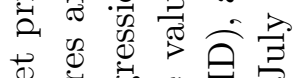



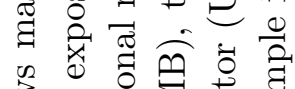





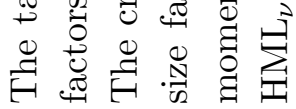


Figure 1: Regression coefficients and $R^{2} \mathbf{s}$ in predictive regressions
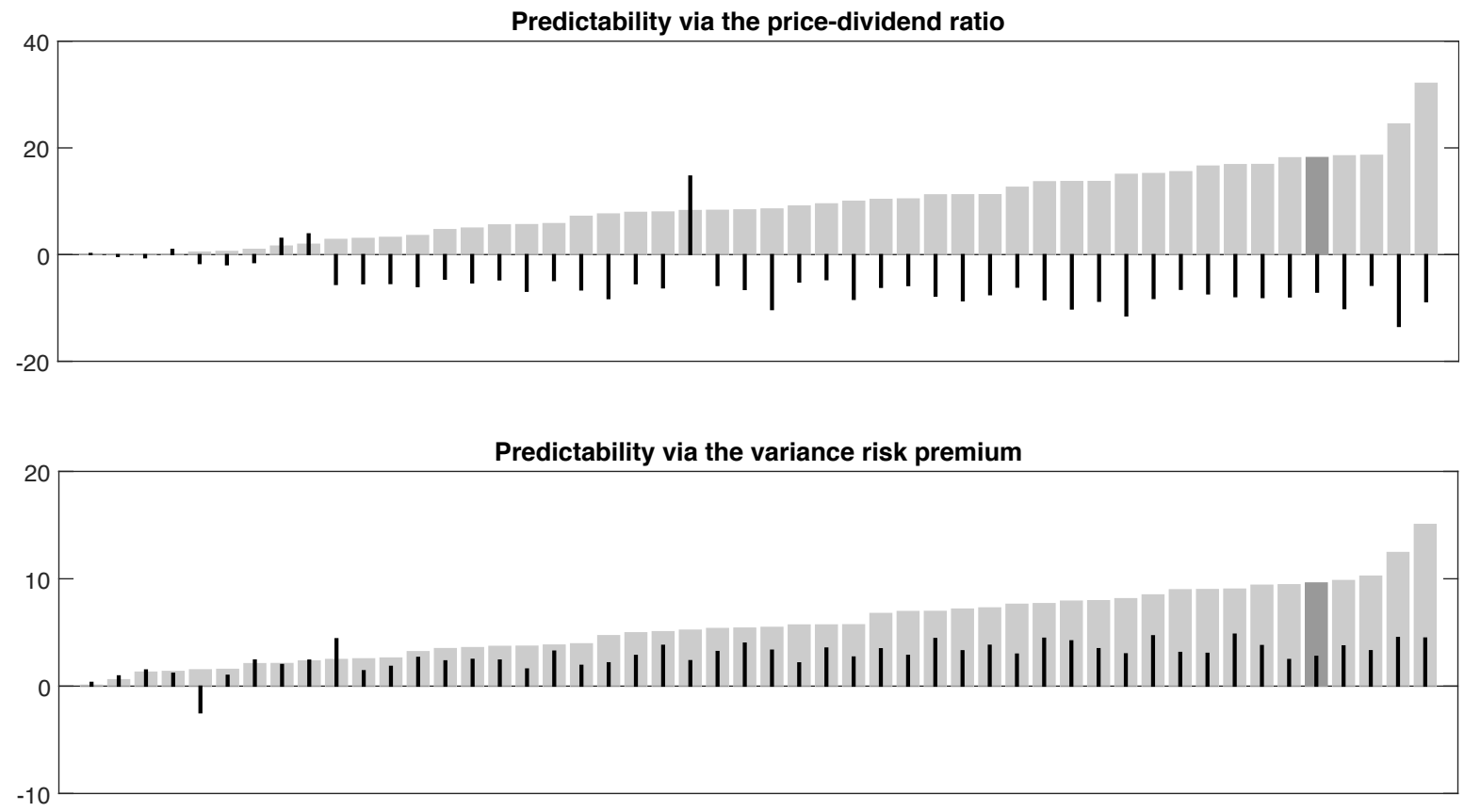

The figure shows $R^{2} \mathrm{~s}$ and slope coefficients from predictive regressions for 49 industry portfolio returns and the market portfolio (dark gray bar). We run the regression $r_{t+1, t+h}^{i}-r_{t+1, t+h}^{f}=a_{i}+b_{i} x_{t}+\epsilon_{t+h}^{i}$, where $r^{i}$ denotes the $\log$ return on the particular portfolio $i, r^{f}$ is the risk-free rate, $x$ is the predictor variable, and $\epsilon^{i}$ represents a mean zero noise term. The coefficients $a$ and $b$ are estimated for a return horizon $h$ of 12 months when the market price-dividend ratio is used as the predictor variable (upper graph). With the variance risk premium as the predictor variable (lower graph), this horizon is 4 months. The data for the portfolio returns are taken from Kenneth French's data library. The price-dividend ratio and the variance risk premium are obtained from Amit Goyal's and Hao Zhous's webpage, respectively. The sample period is 1990/01 - 2018/06. Slope coefficients and $R^{2}$ s are expressed in percentage points. The predictor variables are standardized such that the slope coefficients can be interpreted as reaction of returns on a positive one standard deviation shock in the predictors. 
Figure 2: Rank correlation between predictive slope coefficients

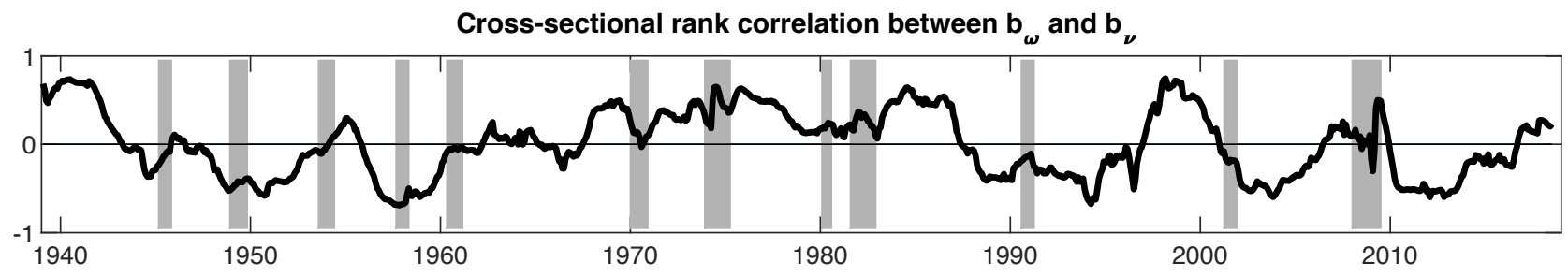

6-year rolling correlation between price-dividend ratio and variance risk premium



The upper graph shows the monthly time series of the cross-sectional rank correlation between the estimated slope coefficients $b_{\nu}$ and $b_{\omega}$. The lower graph shows the monthly time series of correlation coefficients between the price-dividend ratio and variance risk premium. The correlation coefficient for a given month is estimated from data over the preceding six years. The shaded areas indicate NBER recessions. 
Figure 3: Average portfolio numbers

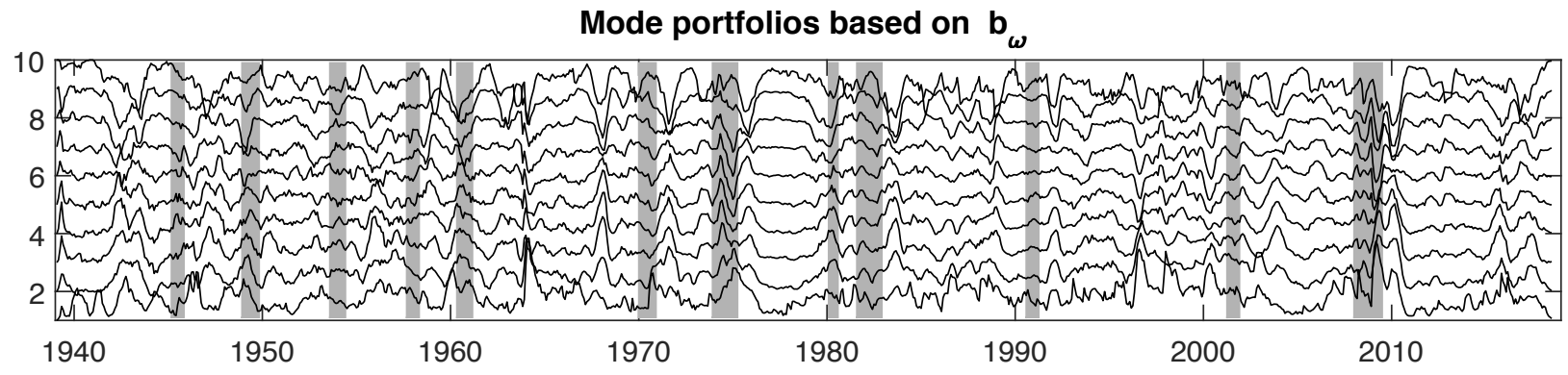

Mode portfolios based on $b_{\nu}$



Mode portfolios based on momentum

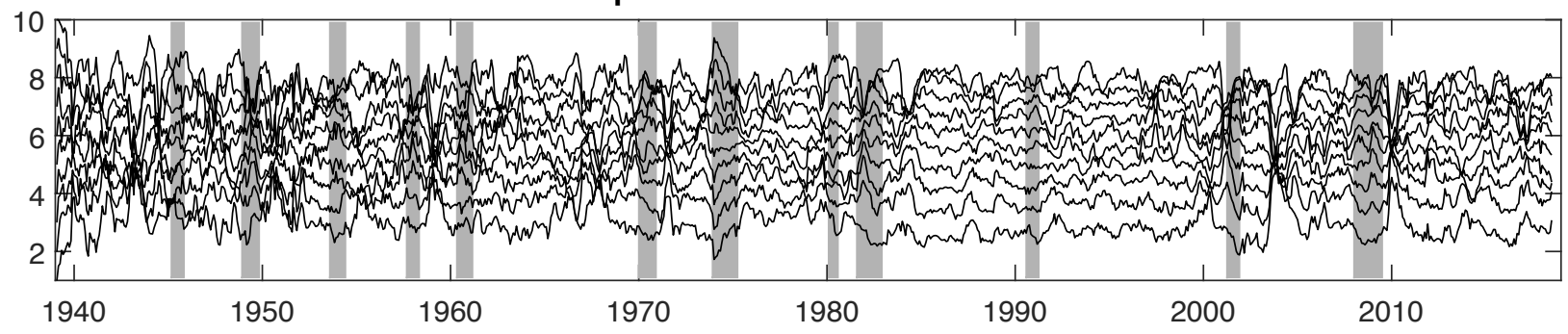

The figure shows the time series of average portfolio numbers for mode portfolios formed on the basis of the estimated regressions coefficients $b_{\omega}$ (upper graph), $b_{\nu}$ (middle graph), and momentum (lower graph). The construction of mode portfolios is explained in Section 4.1. The portfolio number is equal to 1 (10) for stocks in the lowest (highest) decile for the respective sorting criterion. The shaded areas indicate NBER recessions. 
Figure 4: Decile breakpoints for portfolio formation

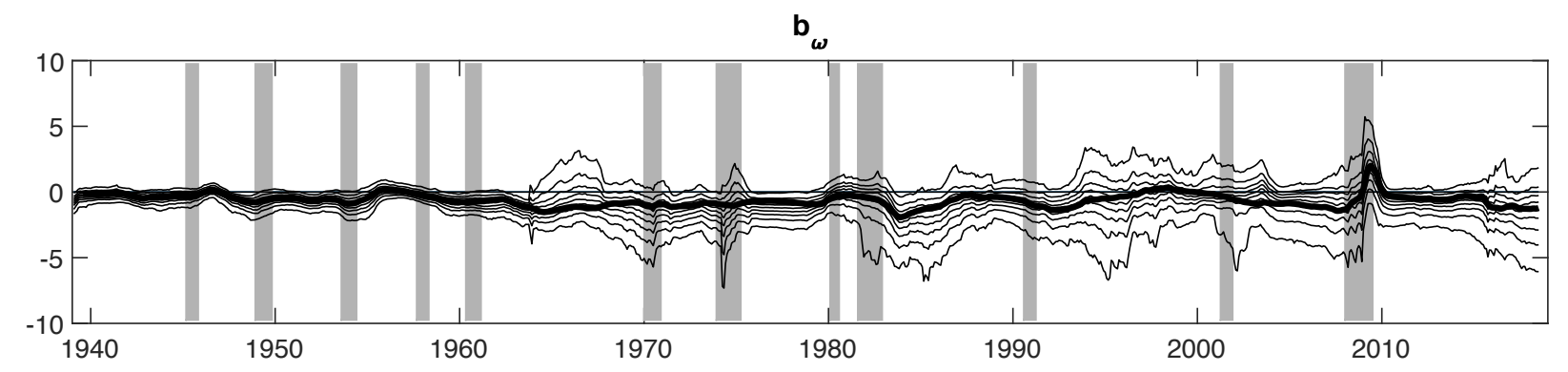

$\mathbf{b}_{\nu}$

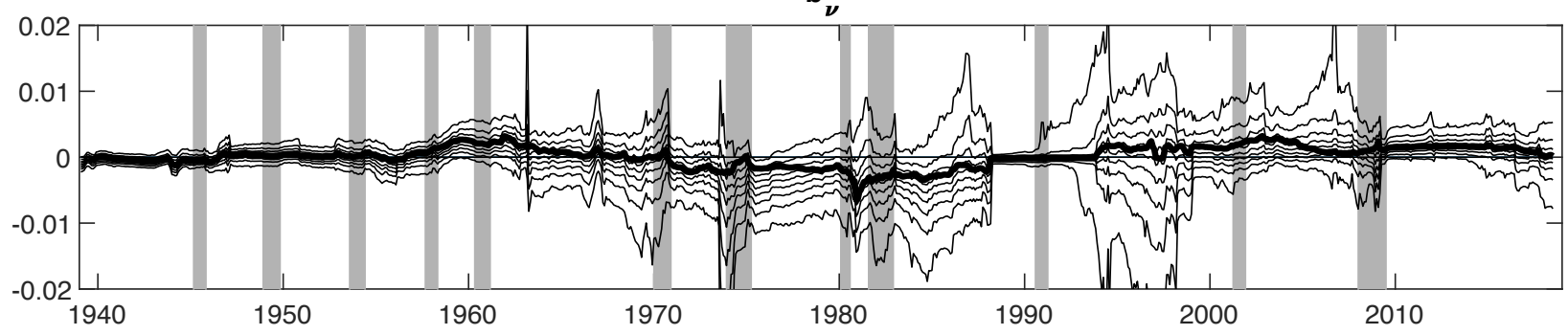

The figure shows the time series of decile breakpoints from the cross-sectional distributions of the estimated slope coefficients $b_{\omega}$ (upper graph) and $b_{\nu}$ (lower graph). The bold black lines represent the slope coefficients of the market portfolio. The shaded areas indicate NBER recessions.

\section{Figure 5: Correlation between HML portfolios}

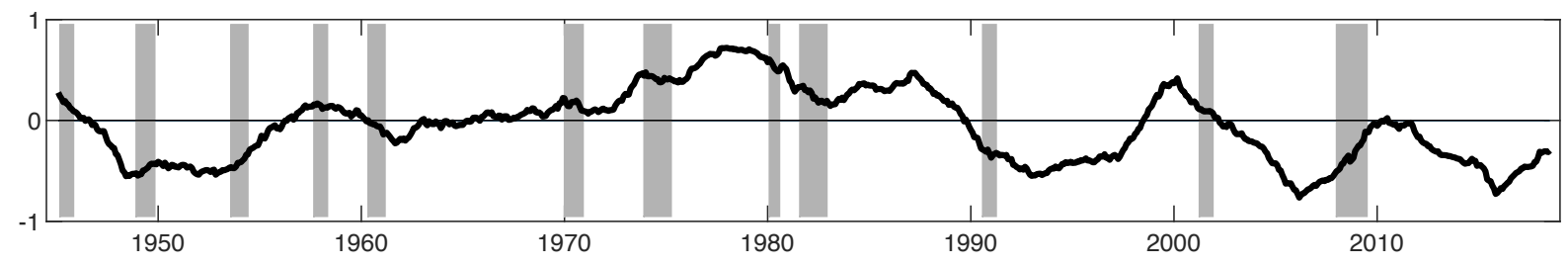

This figure shows the time series of correlation coefficients between the returns on $\mathrm{HML}_{\omega}$ and $\mathrm{HML}_{\nu}$. The correlation coefficient for a given month is estimated from data over the preceding six years. The shaded areas indicate NBER recessions. 


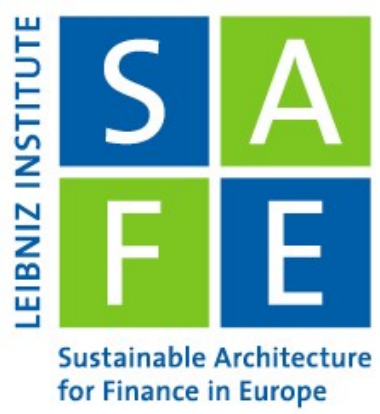

\section{Recent Issues}

No. 288 Michele Costola, Michael Nofer, Oliver Hinz, Loriana Pelizzon

No. 287 Kevin Bauer, Nicolas Pfeuffer, Benjamin M. Abdel-Karim, Oliver Hinz, Michael Kosfeld

No. 286 Andreass Hackethal, Michael Kirchler, Christine Laudenbach, Michael Razen, Annika Weber

No. 285 Elena Carletti, Tommaso Oliviero, Marco Pagano, Loriana Pelizzon, Marti G. Subrahmanyam

No. 284 Monica Billio, Michele Costola, Iva Hristova, Carmelo Latino, Loriana Pelizzon

No. 283 Jannis Bischof, Christian Laux, Christian Leuz

No. 282 Daniel Munevar, Grygoriy Pustovit

No. 281 Kevin Bauer

No. 280 Konstantin Bräuer, Andreas Hackethal, Tobin Hanspal

No. 279 Tobin Hanspal, Annika Weber, Johannes Wohlfart

No. 278 Sandra Eckert

No. 277 Dominique M. Lammer, Tobin Hanspal, Andreas Hackethal

No. 276 Massimiliano Caporin, Loriana Pelizzon, Alberto Plazzi
Machine Learning Sentiment Analysis, COVID-19 News and Stock Market Reactions

The Terminator of Social Welfare? The Economic Consequences of Algorithmic Discrimination

On the (Ir)Relevance of Monetary Incentives in Risk Preference Elicitation Experiments

The COVID-19 Shock and Equity Shortfall: Firm-Level Evidence from Italy

Inside the ESG Ratings: (Dis)agreement and Performance

Accounting for Financial Stability: Bank Disclosure and Loss Recognition in the Financial Crisis

Back to the Future: A Sovereign Debt Standstill Mechanism IMF Article VIII, Section 2 (b)

How did we do? The Impact of Relative Performance Feedback on Intergroup Hostilities

Consuming Dividends

Exposure to the COVID-19 Stock Market Crash and its Effect on Household Expectations

EU Agencies in Banking and Energy Between Institutional and Policy Centralisation

Who Are the Bitcoin Investors? Evidence from Indirect Cryptocurrency Investments

Does Monetary Policy Impact International Market Co-Movements? 